\title{
Showing Off or Laying Low? The Economics of Psych-outs
}

Philipp Denter ${ }^{1}$

John Morgan²

Dana (D.) Sisak ${ }^{3}$

1: Universidad Carlos III de Madrid

2: University of California, Berkeley

3: Erasmus University Rotterdam; Tinbergen Institute, The Netherlands 
Tinbergen Institute is the graduate school and research institute in economics of Erasmus University Rotterdam, the University of Amsterdam and VU University Amsterdam.

Contact: discussionpapers@tinbergen.nl

More TI discussion papers can be downloaded at the Tinbergen Site

Tinbergen Institute has two locations:

Tinbergen Institute Amsterdam

Gustav Mahlerplein 117

1082 MS Amsterdam

The Netherlands

Tel.: +31(0)20 5984580

Tinbergen Institute Rotterdam

Burg. Oudlaan 50

3062 PA Rotterdam

The Netherlands

Tel.: +31(0)10408 8900 


\title{
Showing Off or Laying Low? The Economics of Psych-outs*
}

\author{
Philipp Denter \\ Universidad Carlos III de Madrid \\ Department of Economics \\ pdenter@eco.uc3m.es
}

\author{
John Morgan \\ University of California, Berkeley \\ Haas School of Business \\ morgan@haas.berkeley.edu
}

\author{
Dana Sisak \\ Erasmus University Rotterdam \& \\ Tinbergen Institute \\ sisak@ese.eur.nl
}

April 2018

${ }^{*}$ The paper is loosely based on an earlier working paper with the title "Where Ignorance is Bliss, 'tis Folly to be Wise": Transparency in Contests which appears as a chapter in the PhD theses of Dana Sisak and Philipp Denter. For valuable comments and suggestions, we would like to thank Suzanne Bijkerk, Anne Boring, Micael Castanheira, Marco Celentani, Luis Corchón, Benoît Crutzen, Josse Delfgaauw, Robert Dur, Christian Ewerhardt, Boris Ginzburg, Leif Helland, Sacha Kapoor, Vladimir Karamychev, Antoine Loeper, Jingfeng Lu, Álvaro Name, Diego Moreno, Christian Riis, Antonio Romero, Johannes Schneider, Cedric Wasser, Jun Xiao, participants of the 2016 SAET congress, of the 2016 APET meeting, the 2017 Erasmus Political Economy Workshop, the 2017 workshop on Contests: Theory and Evidence in Norwich, the 2017 workshop in Political Economy in Konstanz, the 2017 Bruneck workshop in Political Economy as well as seminar audiences at Erasmus University Rotterdam, Universidad Carlos III de Madrid, University of Lüneburg, BI Norwegian Business School, CERGE-EI, University of Mannheim, and University of St. Gallen. Dana Sisak and Philipp Denter gratefully acknowledge the financial support of the Swiss National Science Foundation through grants PBSGP1-135426 (Denter) and PBSGP1-130765 (Sisak). Philipp Denter gratefully acknowledges the support from the Ministerio Economia y Competitividad (Spain) through grants ECO2014-55953-P and MDM 2014-0431. Of course, all errors are our own. 


\begin{abstract}
We study situations where a new entrant with privately known talent competes with an incumbent whose talent is common knowledge. Competition takes the form of a rank-order tournament. Prior to the competition, the newbie can "show off," i.e., send a talent revealing costly signal. We find that incentives to show off can go in either direction-more talented types may wish to mimic less talented ones or the reverse, depending on the newbie's talent distribution compared to the one of the incumbent. In equilibrium though, showing off occurs only when the newbie is exceptionally talented compared to the incumbent. Surprisingly, showing off occurs to the benefit of both parties; the newbie benefits for obvious reasons, the incumbent by economizing on wasted effort when overmatched. We use our findings to study the broader consequences of showing off, which is discouraged in many cultures through implicit social norms. We show that norms against showing off raise total effort but worsen talent selection, and are thus appropriate only when effort is society's main concern.
\end{abstract}

Keywords: Showing Off, Contests, Norms

JEL-Classification: D23, D83, M52 


\section{Introduction}

In a way, Barry was coming home. Born in Honolulu, he moved to Jakarta at age four and remained there until fifth grade. Because he stood out in school, his grandparents worked hard to secure him a slot at Punahou Academy, the best private school in Hawaii at the time. Darker, taller, and gawkier than the other boys, Barry was a curiosity on his first day in class 1 While he knew a great deal about Punahou, his classmates knew little about him. And so, when his teacher asked her first question, Barry faced the dilemma of all new kids at school, to raise his hand or to stay quiet. When Barry went to college at Columbia, he was still different, one of the few black students attending at the time. He knew much about Columbia and its storied history, but, to his classmates, he was a man apart, an enigma. And he faced the same dilemma - to stand out or lay low.

Years later, Barry, now going by his given name, Barack, ran for senate in Illinois. He was still a cipher, an unknown commodity in the constellation of power in the Democratic party. Again he chose between standing out or laying low, but this time standing out meant performing on a world stage, delivering the keynote address at the 2004 Democratic National Convention. The party hoped his speech would deter strong contenders in the upcoming contest for the thus far Republican-held Senate seat in Illinois 2 Even today Obama's keynote address is viewed as a great piece of political theater. The rest of Barry's story is well known. He cruised to victory in the Senate race, and not long after, won another election, one that made him 44th President of the United States of America.

While Obama's story, Barry's story, is singular in its events and final outcome, the dilemmas he faced are not. Whether in the workplace, the political arena, high school, or college, the "new kid" must choose between standing out or laying low 3 A good use of this strategy will soften subsequent competition, while a wrong decision may lead to an escalation of rivalry. In this paper, we investigate the economics of showing off, laying low, and psyching out.

In our archetypal situation, a newbie competes against an incumbent for a prize. Both know the incumbent's ability, but the newbie's ability is a mystery to the incumbent. Prior to the competition, the newbie can show off, i.e., send a talent revealing costly signal, or lay low. We find that newbies are often better served by laying low. Only newbies that are exceptional, relative to the incumbent, benefit from showing off in equilibrium. We refer to this finding as "The Law of

\footnotetext{
${ }^{1}$ https://www.washingtonpost.com/opinions/how-obama-became-black/2012/06/14/gJQA8CnKdV_story . html?utm_term=.1a4eb438ae0a

2 "On June 25th, Obama's Republican opponent, Jack Ryan, dropped out of the race, and state and national GOP leaders floated big-time names as a replacement, from former governor Jim Edgar to ex-Bears coach Mike Ditka. The Democrats hoped that giving Obama the high-profile speaking slot would scare away potentially tough Republican challengers." http://www.chicagomag.com/Chicago-Magazine/June-2007/The-Speech/

${ }^{3}$ Many workplaces feature some form of competitive incentives. For example, Cowgill (2015) shows that relative performance evaluation co-determines wages for $77 \%$ of workers in the United States. Such competition motivates effort, but the nature of incentives depends on relative ability as well as beliefs about a competitor's relative ability (Brown, 2011). Horizontal movement of workers is commonplace. For example, Fallick et al. (2006) document that between 1994 and 2001 more than 2.4\% of employees in Silicon Valley changed their employer within the valley on a monthly base. Consequently, asymmetries in the information about a co-worker's talent are important: information about a new hire's talent is inherently less precise.
} 
Exceptionalism" - being better is not enough.

The point of showing off is to convince the incumbent to compete less intensely. Whether revealing talent achieves that depends on relative ability. Newbies that are similar in ability to the incumbent motivate the incumbent to compete harder. These newbies are well advised to lay low. Very low ability newbies appease the incumbent and thus have an incentive to reveal their talent. But for them showing off is very costly and they are not able to credibly reveal their type in equilibrium. It is the exceptional newbies who psych out competition by showing off and for whom showing off is relatively cheap at the same time. We identify the threshold where psych outs become possible and study its properties.

To illustrate the incentives for showing off, consider a swim meet where top male high school athletes compete against a "mystery swimmer," whose identity is withheld by the competition organizer. At his discretion, the mystery swimmer can, if he wishes, leak his identity to the press in advance of the meet. If the mystery swimmer is Mark Spitz, an Olympic champion, but well past his prime, laying low is optimal - revealing his identity will cause the other swimmers to intensify their level of preparation and performance, forcing Spitz to work harder and reducing his chances of winning. On the other hand, if Michael Phelps is the mystery swimmer, leaking is optimal since the high school athletes will see that they have little chance of winning and hence little incentive to prepare or try very hard in the meet. This, in turn, permits Phelps to economize on effort. We identify the factors determining when a Spitz becomes a Phelps.

Finally, we examine the economics of showing off from a societal perspective. While the students of Punahou might prefer to minimize effort, their teachers surely have a different objective. We show that when society cares about aggregate effort, showing off should be strongly discouraged. In many cultures this discouragement takes the form of a social norm against showing off. For example, the English-speaking world uses the metaphor of "Cutting Down the Tall Poppies." 4 In schools, tall poppies are straight-A students who are voluble in demonstrating their intelligence. In the workplace, they are show-offs who showcase their expertise during watercooler discussions and lunch breaks. Cutting down the tall poppies means punishing and thus discouraging showing off behavior. Our analysis reveals that such norms, which nowadays often seem out of place, can be functional and create social value. By limiting showing off opportunities, society shuts down this channel of discouraging others as a means to economize on effort.

Casual empiricism, though, suggests exceptions to this rule: Silicon Valley startups seem to owe much of their success to letting the tall poppies bloom. In these settings, talent identification and retention determines success. We show that a norm against showing off is detrimental when selecting the exceptional is the goal. Thus, the same model of showing off can account for apparently vastly different behavioral norms.

To be precise, we amend the standard contest model to allow for the costly signaling of ability in a situation where information is asymmetric - one party's abilities are known to all while the

\footnotetext{
${ }^{4}$ This metaphor dates back to accounts by Herodotus that describe how Thrasybulus led a herald from Periander through a wheat field. In response to the herald's question of how he would most safely govern his city, Thrasybulus silently cuts down the tallest ears of wheat. (Herodotus, The Histories, Book 5, 92-f)
} 
other's are unknown and private knowledge. Signaling costs are perfectly correlated with ability. In this setting, our main results are the following:

- There always exists a threshold equilibrium in which, if any, only newbie types that are exceptionally talented show off. Less talented newbies lay low and their types remain unknown.

- Showing off and laying low are used by competitors to soften competition to their mutual benefit. Doing so, however, harms a society mainly interested in total effort. A norm against showing off may serve as a remedy and increases aggregate effort.

- The possibility of showing off tends to accentuate competitors' differences and thereby improves selection efficiency. Thus a norm against showing off is detrimental to a society interested in selecting the most able competitor.

We now place our findings in the context of the extant literature. Classical signaling games in the tradition of Spence (1973) also deal with the question of whether to show off (see e.g. Feltovich et al., 2002, or Daley and Green, 2014, for some more recent contributions to this strand of literature). In contrast to our paper, here the showing off is addressed to a principal and not to a competitor.

The extant contest literature mainly focuses on driving effort or selection by manipulating various aspects of the contest such as prize amounts, numbers of players, and information disclosed by the contest organizer. We focus on the equilibrium "culture" of information revelation that prevails among competitors.

A branch of the literature studies contest structure including the allocation of prize money and timing in the resolution mechanics of the contest itself 5 Another branch studies how the principal might wish to manipulate the information competitors have about one another; for example, by releasing information about the competitors' abilities before the start of the competition. Leading examples of this branch are Ederer (2010), Klein and Schmutzler (2017), Zhang and Zhou (2016), Lu et al. (2016), or Crutzen et al. (2013). By contrast, we focus on the choices that would be made when the agent, rather than the principal, decides.

There is a small literature that also focuses on disclosure by agents. Important examples are Kovenock et al. (2015) and Wu and Zheng (2017), who study ex-ante commitment by the competitors to disclose information costlessly, as well as Katsenos (2009) and Heiinen and Schoonbeek (2017), who also analyze agents' incentives to signal their types 6 Hörner and Sahuguet (2007) study a competitor's incentives to manipulate information in an auction setting through an aggressive or cautious opening bid. We complement these papers in that we also study agents'

\footnotetext{
${ }^{5}$ For example, Moldovanu and Sela (2001), Clark and Riis (1998), or Sisak (2009) focus on optimal prize division with a given budget. Gradstein and Konrad (1999) and Moldovanu and Sela (2006) analyze one-shot contests versus tournaments with multiple stages. Yildirim (2005), Klumpp and Polborn (2006), Konrad and Kovenock (2009), Denter and Sisak (2015, 2016), or Seel and Strack (2016) focus on dynamics in effort choices where the same competitors expend effort repeatedly against each other.

${ }^{6}$ In contrast to Katsenos (2009) and Heiinen and Schoonbeek (2017), who confine their analyses to binary type distributions, we consider generic continuous and differentiable type distributions.
} 
incentives to reveal their type before entering into competition. We innovate by studying the social desirability of norms against showing off.

While the question whether to show off is clearly relevant for human interactions, animals also show off to signal their talent. For instance, scientists have studied the phenomenon of roaring behavior by stags during the red deer's mating season. A challenger initiates roaring against the incumbent harem holder. After assessing one another during this roaring strength display, the red deer stags decide whether to enter into direct conflict (see for example Payne and Pagel, 1997). Critically, the incumbent's subsequent aggressiveness depends on the information gained in the roaring phase of the meeting. Recent studies found that also octopi engage in costly signaling before potentially entering into conflict. They find that octopus colouring and body posture are correlated with escalation of disputes (Scheel et al., 2016). The testable predictions we offer apply as much to animal behavior as human.

There is a vast literature examining how institutions and norms form, and how they impact policy 7 Many scholars argue that norms correct for positive or negative externalities and thus a norm is likely to arise in settings where it is socially beneficial (see e.g. Fehr and Fischbacher, 2004). Relatedly, a behavioral regularity noted in the experimental economics literature is that a more socially beneficial norm of behavior (in a broad sense) is more likely to be adopted 8

We are agnostic on how norms emerge. Rather, we take as given that the likelihood of a norm prevailing depends on its social desirability. Our contribution, relative to the extant literature, is to apply this metric to showing off situations embedded in contests. As described above, norms against showing off are prevalent in many contexts, though they are noticeably absent in others. Applying this notion of norm emergence, we find that a norm against showing off is more likely to emerge when society benefits from aggregate effort expended in the contest and less likely when selection of talent is society's primary goal.

The paper is organized as follows. The next section, Section 2 introduces the model. Section 3 features the main analysis where we study showing off by the newbie in Subsection 3.1 . In Subsection 3.2 we study the incumbent's perspective on showing off. In Section 4 we study the effects of a norm that punishes individual showing off behavior. Finally, in Section 5 we study the implications of 'productive' showing off, i.e. showing off that not only reveals information but also translates into effective effort. Section $[$ concludes. All proofs are relegated to the appendix.

\section{The Model}

As argued above, asymmetries in information for example about a co-worker's talent are important, since information about a new hire's talent is inherently less precise than information about well

\footnotetext{
${ }^{7}$ See e.g. Acemoglu and Robinson (2016) for the importance of norms for the emergence of different institutions, Sliwka (2007) for how norms affect organizational design, Name Correa and Yildirim (2016) for how norms affect charitable giving, or Bowles and Polanía-Reves (2012) for a survey.

Z Zelmer (2003) provides a meta analysis of giving behavior in linear public goods games where a higher marginal per capita return tends to increase contributions while Parravano and Poulsen (2015) show that stake size increases coordination on label-salient strategies for symmetric coordination games.
} 
established, or incumbent, competitors. The model we construct is a parsimonious representation of such an environment that serves to highlight the main forces at play. Two competitors vie for a prize, which goes to the better performer and whose value we normalize at 1 . The loser receives a consolation prize, which we normalize at zero 9 These competitors could be two middle managers competing for a bonus, political rivals competing for office, or students competing to be valedictorian.

Let $x_{i}$ denote competitor $i$ 's effort, where both players choose effort simultaneously. When two managers compete, this effort can be thought of as the thoroughness of the market research each of them conducts to use as the basis for decisions that affect the success of the company. A competitor's realized "performance" is a combination of her luck and effort; thus, it may well be the case that the competitor who exerts more effort still loses the contest. Formally, let $\epsilon_{i}$ be the luck component of performance and suppose that measured performance takes the form:

$$
y_{i}=x_{i} \cdot \epsilon_{i}
$$

A competitor's "luck" consists of a realization of a Weibull (maximum) distribution with a mean equal to one. Thus, on average, a player's performance corresponds to her effort, and neither player is "luckier" than her rival.

The principal awards the prize to the better performing competitor, i.e., the competitor with the higher value of $y_{i}$. Thus, while effort is helpful in securing the prize, exerting more effort than a rival does not guarantee success. Our formulation of the luck component of performance produces a convenient specification relating a competitor's chance of success to her effort. In particular, the chances of success art 10

$$
p_{i}=\frac{x_{i}}{x_{i}+x_{j}} \quad \text { and } \quad p_{j}=1-p_{i} .
$$

This formulation, often called the lottery contest success function, proves extremely tractable, so much so that it is virtually standard in examining contests and tournaments 11

Competitors are risk neutral and differ in ability/talent. We model this difference by assuming that a more talented person has a lower marginal cost of effort, $c_{i}$. Returning to our leading example, a more talented manager can produce reports with a given level of thoroughness more quickly than a less talented manager, i.e., she incurs lower costs.

While each competitor knows her own marginal costs (ability) at the time of effort choice, information about the other player may differ. In particular, we assume that the talent of competitor $I$, the incumbent, is common knowledge, whereas the talent of her rival the newbie, whose identity

\footnotetext{
${ }^{9}$ One may worry about normalizing both the winning and losing prize, but, in a contest setting, this is without loss of generality. Effort in a contest depends solely on the spread between the value of the prizes, rather than their level; thus we have essentially normalized the spread to be equal to one "util." Normalizing the prize spread is also without loss of generality as we allow for general constant marginal costs of effort. A linear transformation of the utility function, i.e. dividing by a constant, leaves strategic incentives intact.

${ }^{10} \mathrm{See} \mathrm{Fu}$ and $\mathrm{Lu}(2012)$ for details on how to derive this specification.

${ }^{11}$ The functional form of equation (1) is problematic when both players choose zero effort. Following the literature, we assume that a coin flip determines the winner in this case. See for example Konrad, 2009 or Sisak, 2009 for surveys of the vast literature using this specification.
} 


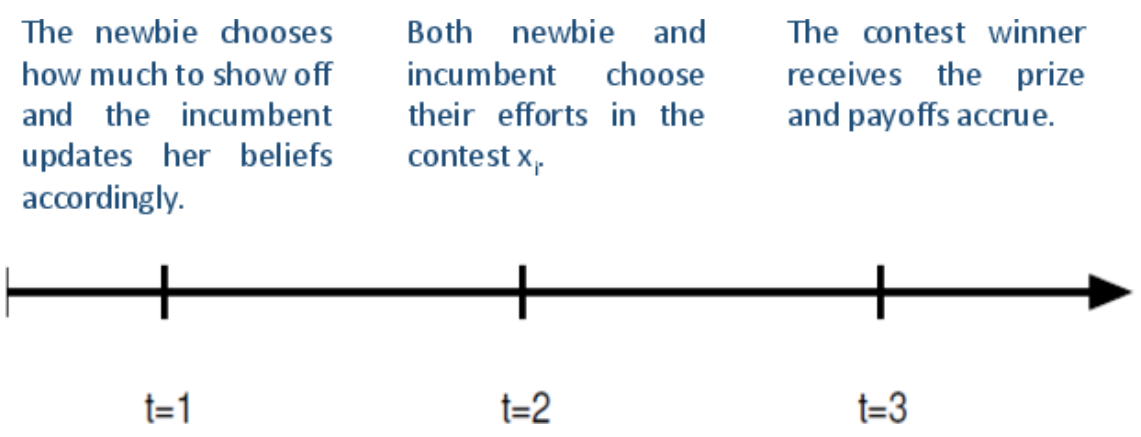

Figure 1: Sequence of moves.

we denote by $N$, is private information. The asymmetry describes common hiring situations where an internal candidate faces off against an external candidate or where a new salesperson competes against a veteran incumbent. It also serves the additional purpose of highlighting the main forces in the economics of showing off, which are only relevant in private information settings, while minimizing the complexity of the analysis 12

Prior to both party's effort allocations, the newbie has the opportunity to "show off" by choosing $s_{N} \geq 0$, i.e., to engage in costly (but non performance related) displays meant to signal his ability 13 Such displays can take many forms. In a corporate setting they might consist of watercooler conversations or especially dazzling presentations. In an academic setting they might consist of incisive seminar comments from an Assistant Professor seeking tenure. Importantly, the cost of such displays varies with the newbie's talent. We assume that the marginal cost of a unit of "showing off" is equal to the cost of one unit of expected performance, $c_{N}$. Since the incumbent does not know the newbie's talent, such displays can affect the incumbent's beliefs and hence alter the strategic circumstances of performance driven effort. Studying when the newbie shows off, and how this impacts effort choices, forms the heart of the paper. Figure 1 summarizes the timing of moves.

Formally, the incumbent $I$ 's cost parameter $c_{I}$ is common knowledge at the beginning of the game, while the newbie's cost $c_{N}$ is a random variable from the perspective of the incumbent with a commonly known $\mathrm{CDF} F\left(c_{N}\right)$ over some interval $\mathcal{S}_{N}=\left[c_{L}, c_{H}\right]$. We assume that $F\left(c_{N}\right)$ is twice differentiable and strictly increasing on $\mathcal{S}_{N}=\left[c_{L}, c_{H}\right]$. While our results hold for continuous CDFs, the intuition and economic forces at work are most clearly visible when competitor $N$ has only two types, i.e., when $\mathcal{S}_{N}=\mathcal{S}_{N}^{B}=\left\{c_{L}, c_{H}\right\}$ and $f\left(c_{N}\right)=\mathbf{q}^{2}=(q, 1-q)$, with $q \in(0,1) 14$

Throughout we focus on interior equilibria, that is equilibria in which all types of both players choose positive effort in the contest. A sufficient condition for interiority is 15

\footnotetext{
${ }^{12}$ Our results readily extend to situations of two-sided asymmetric information where ability distributions differ. In particular, our results may be thought of as describing the limiting value of a sequence of equilibria where the ability of one player converges to the Dirac distribution. Katsenos (2009), on the other hand, offers some insights on the limiting case where ability distributions are the same, i.e., either competitor is of type $c_{L}$ with probability $q$ and type $c_{H}$ with probability $1-q$. We discuss his findings and relate them to our results in Subsection 3.1

${ }^{13}$ In Section 5 we relax this assumption and allow for directly productive signaling effort.

${ }^{14}$ Note that this binary scenario does not satisfy the formal conditions on $F\left(c_{N}\right)$.

${ }^{15}$ Corner solutions can arise when all of the probability mass is centered around $c_{L}$ and $c_{I}=c_{L}$. In such cases,
} 
Assumption 1. $2 c_{L} \geq c_{H} \geq c_{I} \geq c_{L}$.

If the incumbent does not learn the newbie's type, her expected payoff equals

$$
\pi_{I}\left(x_{I}\right)=\int_{c_{L}}^{c_{H}}\left[\frac{x_{I}}{x_{I}+x_{N}\left(c_{N}\right)}\right] d F\left(c_{N}\right)-c_{I} x_{I} .
$$

where $x_{N}\left(c_{N}\right)$ denotes the effort of a newbie of type $c_{N}$. If she does learn the newbie's type, her expected payoff equals

$$
\pi_{I}\left(x_{I}\right)=\frac{x_{I}}{x_{I}+x_{N}}-c_{I} x_{I}
$$

The expected payoff for a newbie of type $c_{N}$ equals

$$
\pi_{N}\left(x_{N}, s_{N}\right)=\frac{x_{N}}{x_{I}+x_{N}}-c_{N}\left(x_{N}+s_{N}\right), \quad c_{N} \in \mathcal{S}_{N}
$$

Before starting with the details of the analysis, we define the kind of equilibria we will focus on in the following:

Definition 1 (Threshold equilibrium). A threshold equilibrium of the showing off game is a Perfect Bayesian Equilibrium in which a threshold $c_{Z}$ exists such that all newbies with $c_{N}<c_{Z}$ (if any) show off, while all others refrain and lay low. The incumbent observes the degree of showing off and updates her beliefs accordingly. Both players choose efforts in the contest given these beliefs.

As usual, there may be multiple Perfect Bayesian Equilibria in signaling games. To avoid this, we restrict off equilibrium beliefs using the Intuitive Criterion by Cho and Kreps (1987) when there are only two types of newbies, and D1, which was also developed by Cho and Kreps (1987), in the general case 16

\section{Analysis}

\subsection{Showing Off}

We now study the newbie's incentives to show off. Showing off is a worthwhile endeavour if it transmits information to the incumbent, and this information transmission leads to outcomes which the newbie considers beneficial. Two observations are central to understanding showing

weaker newbie types optimally choose zero effort. Assumption 1 rules this out. Note that most of our results also apply under a less strict version of this assumption, $4 c_{L} \geq c_{H} \geq c_{I} \geq c_{L}$, only Proposition 3 and Theorem 3 rely on it. These results do hold in a slightly weaker form. For details please consult Appendices D and F

${ }^{16}$ As we will see in Proposition 1 below, using the Intuitive Criterion by Cho and Kreps (1987) produces a unique equilibrium outcome in the binary case. With more than two types, however, the Intuitive Criterion fails to make unique predictions, and other refinements, such as D1 due to Cho and Kreps (1987) or Universal Divinity due to Banks and Sobel (1987), are needed to yield unique equilibrium predictions, see for example Chapter 13 of Mas-Colell et al. (1995). D1 further refines the set of possible equilibria compared to the intuitive criterion. In particular, D1 restricts off equilibrium beliefs by assigning probability 1 on the type with the greatest incentives to deviate, should an off equilibrium action be chosen. For applications, see for example Bernheim (1994), Kolb (2015), or Daughety and Reinganum (2014). In our model, D1 produces a unique equilibrium outcome, in which the greatest possible fraction of newbies show off, and which is a direct implication of Lemma 5 in the appendix. 

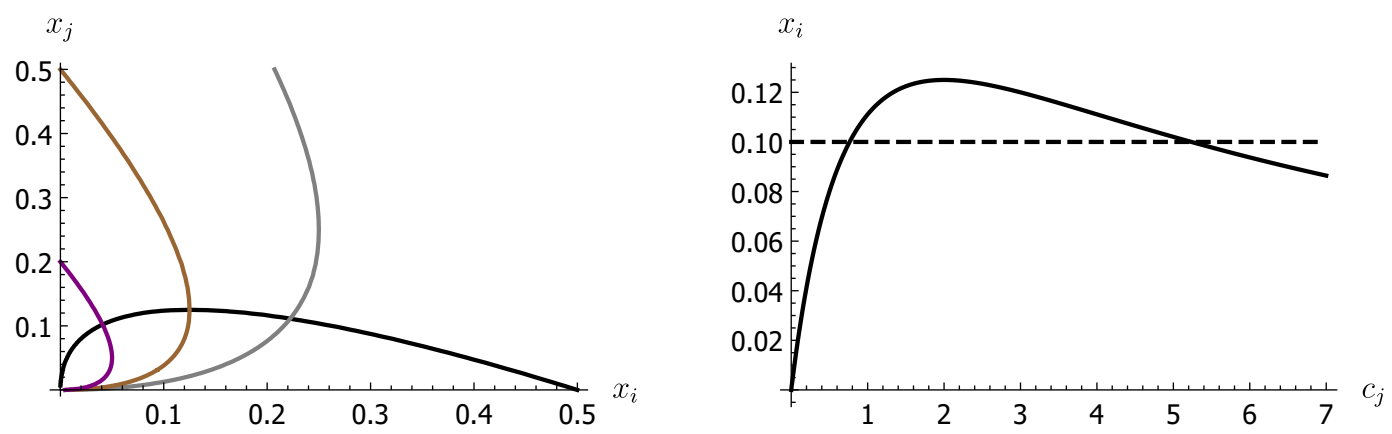

Figure 2: A player's effort is maximal when she faces a competitor of identical talent and decreases strictly when the match gets more unbalanced. Left panel: Best response functions for $i$ and $j$, given $c_{j}=2$ and $c_{i} \in\{1,2,5\}$. Right panel: Equilibrium effort of $i$ with $c_{i}=2$ as a function of $c_{j} \in(0,5]$.

off incentives. First, under complete information, the effort $x_{i}^{C I}\left(c_{-i}\right)$ spent by a player with marginal $\operatorname{cost} c_{i}$ against an opponent with marginal cost $c_{-i}$ in equilibrium is maximal when she faces another player of the same talent, $\bar{x}^{C I}=x_{i}^{C I}\left(c_{i}\right)$, and decreases monotonically when the talent of the opponent increases or decreases. This is shown in Figure 2. Therefore, with potential opponent types drawn from some interval $\left[c_{L}, c_{H}\right]$, the incumbent's minimum effort under complete information will be chosen either against $c_{L}$ or against $c_{H}$, and thus $\underline{x}^{C I}=\min \left\{x_{I}^{C I}\left(c_{L}\right), x_{I}^{C I}\left(c_{H}\right)\right\}$. Second, under asymmetric information, effort of a player who faces an opponent drawn from $\left[c_{L}, c_{H}\right]$ is $x^{A I} \in\left(\underline{x}^{C I}, \bar{x}^{C I}\right)$ for any non-degenerate type distribution (see Lemma 3 in Appendix $\mathbb{B}$ ). That is, the incumbent's asymmetric equilibrium effort always fulfills $x_{I}^{A I} \in\left(\underline{x}^{C I}, x_{I}^{C I}\left(c_{I}\right)\right)$. The newbie always benefits when the incumbent lowers her effort, and hence the best the newbie can do is to convince the incumbent that he is the type against which she is least aggressive, i.e., the type that induces $\underline{x}^{C I}$. This is true for all newbie types. Thus, our first task is to identify this type that induces $\underline{x}^{C I}$.

We can see from Figure 2 that complete information best responses are hump-shaped in the situations that we study and thus every positive complete information equilibrium effort choiceexcept the maximum - can be induced by two different types of opponents. Complete information effort $x_{i}$ against an opponent with marginal cost $c_{j}$ is $x_{i}\left(c_{j}\right)=c_{j} /\left(c_{i}+c_{j}\right)^{2}$, implying that effort is identical against some $c_{j}^{\prime}$ and $c_{j}^{\prime \prime}, c_{j}^{\prime} \geq c_{i} \geq c_{j}^{\prime \prime}$, if and only if $c_{i}=\sqrt{c_{j}^{\prime} c_{j}^{\prime \prime}}$. Moreover, the closer $c_{j}^{\prime}$ and $c_{j}^{\prime \prime}$ to $c_{i}$, the more $i$ spends against both. Consequently, if $c_{I}=\mu_{N}=\sqrt{c_{L} c_{H}}$, the incumbent chooses identical effort against the most and against the least talented newbie, and thus all newbie types are indifferent between making the incumbent believe to be either one (absent signaling costs). If the incumbent is relatively untalented, $c_{I}>\mu_{N}$, the incumbent's lowest complete information effort is against the most talented newbie $c_{L}$, and otherwise against the least talented newbie $c_{H}$. Thus, we have a condition that tells us-depending on just $c_{I}, c_{L}$, and $c_{H}$-what the newbie would like the incumbent to believe.

Note that incentives to show off are different from incentives in standard signaling games à la Spence (1973), where incentives to imitate run in one direction-worse types want to be perceived as better types and thus better types signal to prevent this. In our setting incentives for the newbie can run in either direction, depending on the incumbent's ability. Thus, the same type distribution 
and preferences do not, by themselves, determine the direction of signaling incentives. The reason for this is that the fierceness of subsequent competition depends on the newbie's as well as the incumbent's ability.

The implications of the described forces for showing off are most easily seen when there are only two types of newbies. In this case, if one type of newbie successfully signals his type, the other type is revealed as well. By the arguments above, if $c_{I}<\mu_{N}$ and thus the incumbent is relatively talented, both types would like to signal to have low talent. Both would like to signal to be able otherwise. Because signaling cost are correlated with talent, whenever both would like to show that they are untalented, lower signaling costs allow the more talented newbie type to effectively mimic the less able one, and thus no separating equilibrium exists. In this situation no showing off takes place. To the contrary, when the incumbent has low talent, both types would like to signal to be talented. But now the more talented newbie type can induce a separating equilibrium exactly because he has lower costs of signaling, and in equilibrium all types will be revealed through showing off. Hence, our first conclusion, based on the binary case, is that if the newbie is sufficiently talented, information on the newbie's talent is fully revealed through showing off in equilibrium:

Proposition 1. Assume binary types and let $\mu_{N}=\sqrt{c_{L} c_{H}}$. A unique showing off equilibrium, where the newbie's type is completely revealed, exists if and only if the incumbent is relatively weak in expectation $\left(c_{I} \geq \mu_{N}\right)$. In all other cases, the newbie lays low and no information will be revealed in equilibrium.

The proof of Proposition 1 is contained in Appendix $\mathrm{B}^{17}$ The proposition illustrates what we might coin the "Law of Exceptionalism." It does not suffice to be just more talented than the incumbent for the talented newbie to show off and to psych out the incumbent (i.e., $c_{L}<c_{I}$ ); the advantage needs to be sufficiently large for any given $c_{H}$. This can be seen easily from the condition for showing off to happen: $c_{I}>\sqrt{c_{L} c_{H}} \Leftrightarrow c_{L}<\frac{c_{I}^{2}}{c_{H}}<c_{I}$. A non-exceptional newbie prefers to lay low, as revealing his talent would only sharpen competition.

Note that equilibrium showing off in Proposition 1 does not depend on the particular distribution of newbie types. This is a peculiarity of the binary case, because, in this case, when the talented newbie decides to show off, the untalented newbie's type is also revealed. When there are at least three types of newbies, the distribution of types matters. For example, assume there is a third type $c_{M} \in\left(c_{L}, c_{H}\right)$. The above reasoning about which type everybody wants to mimic remains valid: If the incumbent is strong, $c_{I}<\mu_{N}$, all types would like to signal to have low talent, $c_{H}$. Otherwise high talent, $c_{L}$, induces the lowest incumbent effort under complete information. Moreover, as in the binary scenario, it will not be possible to separate types completely when the incumbent is talented, $c_{I}<\mu_{N}$, because the more talented newbies want to mimic the weakest type $c_{H}$, and they are also able to do this. Generally, for this case there cannot be a separating

\footnotetext{
${ }^{17}$ Note that Proposition 1 and all results that follow pertaining to the binary case locally generalize to a more general class of contest success functions of the form $p_{A}=\frac{f\left(x_{I}\right)}{f\left(x_{I}\right)+f\left(x_{N}\right)}$, where $f\left(x_{i}\right)$ is an increasing and weakly concave function. Around a critical value of $c_{I}$, which generally exists and where full information efforts against $c_{H}$ and $c_{L}$ are equal, all results will be the same. Details are available from the authors upon request.
} 
equilibrium in which $c_{H}$ is revealed truthfully, and thus at least two newbie types need to pool. The only possible partial separating equilibrium is the one in which $c_{L}$ shows off while $c_{M}$ and $c_{H}$ lay low and pool. In this situation, showing off convinces the incumbent that he faces the most talented newbie type, but, unlike in the binary case, not showing off leaves open several levels of newbie talent. How the incumbent reacts to the newbie's laying low depends now on the distribution of types, and this in turn determines showing off incentives. As such, the talent distribution now figures into the talent threshold at which showing off first occurs.

Now we turn to general distributions. In Lemma 1 in Appendix A, we completely characterize equilibrium effort in settings where no showing off occurs. We show that the effort equilibrium is always unique. Next, we add the possibility of showing off in advance of effort determination. As with nearly all signaling games, the freedom to choose beliefs arbitrarily off the equilibrium path produces multiple equilibria. To address such situations, and thereby permit straightforward derivation of comparative statics, we apply the D1 refinement, as is often used in signaling games. This refinement selects the equilibrium where the largest possible set of newbie types show off. We thus denote this equilibrium as the "maximally informative equilibrium" (MIE) in the following and the newbie who is just indifferent between showing off and laying low as the MIE threshold.

We now state the main result from this section:

Theorem 1 (Showing Off and Laying Low). Suppose that newbie types are continuously distributed on $\mathcal{S}_{N}$ according to $F\left(c_{N}\right)$. There exists a unique $\tilde{c}_{I}>c_{L}$ such that if $c_{I}>\tilde{c}_{I}$, a unique MIE threshold $\tilde{c}_{N} \in\left(\frac{c_{I}^{2}}{c_{H}}, c_{I}\right)$ exists. Newbie types $c_{N}$ show off if and only if $c_{N}<\tilde{c}_{N}$, and lay low otherwise. The MIE threshold strictly increases in $c_{I}$ for $c_{I} \in\left(\tilde{c}_{I}, c_{H}\right]$. When $c_{I} \leq \tilde{c}_{I}$, no newbie shows off in equilibrium. $\tilde{c}_{I}$ is implicitly defined by $\tilde{c}_{N}=c_{L}$.

Theorem 1 shows that the impact of subsequent competition on showing off incentives and the Law of Exceptionalism hold in general. Especially noteworthy is that showing off incentives crucially depend on the incumbent's ability - a sufficiently talented incumbent, $c_{I} \leq \tilde{c}_{I}$, destroys incentives for talented newbies to show off, because instead of psyching out the incumbent, it provokes more intense competition.

Figure 3 presents a graphical illustration of Theorem 1 when the newbie's ability is uniformly distributed on $[1,2]$. The solid line represents the MIE threshold, newbie types lying below this threshold wish to show off, those lying above do not. When the incumbent is talented, that is when $c_{I}$ lies to the left of the dotted vertical line $\left(\tilde{c}_{I}\right)$, all newbie types lie above the threshold and no one shows off. As $c_{I}$ increases, so too does the amount of showing off. Indeed, an incumbent corresponding to the worst possible newbie type leads all newbie types to show off. Figure 3 also displays the upper and lower bounds of the MIE threshold, represented by the dashed lines, which are not distribution specific. Thus, regardless of the type distribution, newbie types lying below the lower bound always wish to show off.

One might wonder whether there is a systematic relation between risk and the incentives to show off. No such general relationship exists, as is most easily seen in the binary case. There the geometric mean of newbie types determines the showing off threshold, i.e., showing off occurs if 


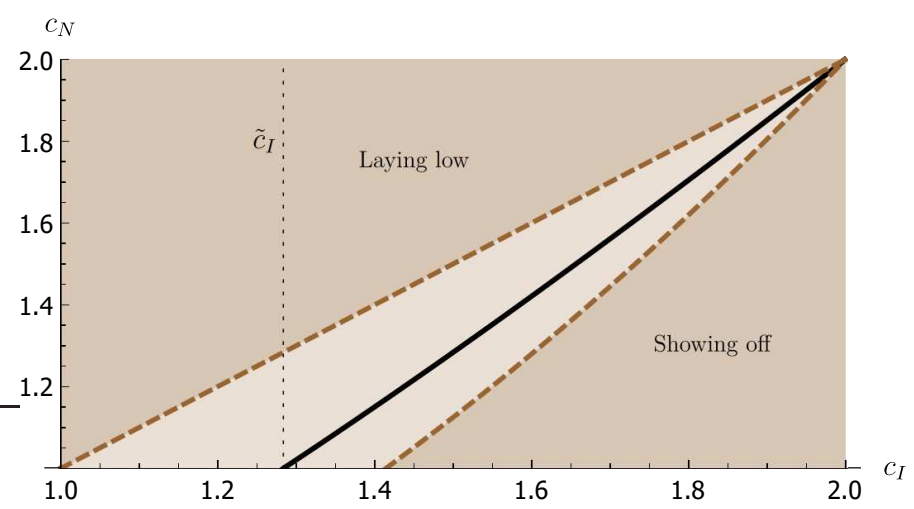

Figure 3: The graphic show the MIE threshold (solid line) when $c_{N} \sim U[1,2]$. The dashed lines represent the bounds of the MIE threshold. All newbie types below the lower bound always show off, independent of the type distribution's details. Similarly, all newbie types above the upper threshold always lay low. The dotted vertical line represents $\tilde{c}_{I}$.

and only if the incumbent's type lies above the threshold. The key thing is to notice that this threshold is independent of the probabilities of the newbie's type. As a consequence, risk may increase or decrease the threshold, depending on how the geometric mean is affected.

At this point it is useful to link our findings to the ones in Katsenos (2009). He studies a two-sided asymmetric information framework where ability distributions of both competitors are the same, i.e., either competitor is of type $c_{L}$ with probability $q$ and type $c_{H}$ with probability $1-q$. He finds that a separating equilibrium-or a showing off equilibrium in our language-only exists if a player's opponent is sufficiently weak in expectation, i.e., when $q$ is sufficiently small. Thus, also with two-sided asymmetric information a variant of our result applies: Only a sufficiently talented competitor shows off.

\subsection{The Incumbent's Perspective}

One might be tempted to think that showing off by the newbie must come at a cost to the incumbent. The underlying intuition suggests that showing off psychs out the incumbent, thus reducing her chance of winning the contest, and hence making her worse off. The flaw in this intuition is that it ignores how the newbie responds to the incumbent's change in effort.

As in the previous section, we start with the binary case to develop intuition. Absent showing off, the incumbent remains uncertain as to the newbie's ability and hence chooses effort somewhere between that which she would choose knowing the newbie is a low type and that when knowing he is a high type, i.e., $x_{I}^{A I} \in\left[\min \left\{x_{I}^{C I}\left(c_{L}\right), x_{I}^{C I}\left(c_{H}\right)\right\}, \max \left\{x_{I}^{C I}\left(c_{L}\right), x_{I}^{C I}\left(c_{H}\right)\right\}\right]$. As we next show, whether showing off harms the incumbent depends on the relationship of this intermediate effort to what an incumbent with commitment power would choose under full information.

To understand this, consider the following hypothetical problem: What effort level would the incumbent choose, if she could commit to any effort level she wishes to? Such a situation is alike a Stackelberg game with the incumbent as the leader and the newbie as the follower as well as full information regarding the newbie's talent. Under full information, it is well-known 


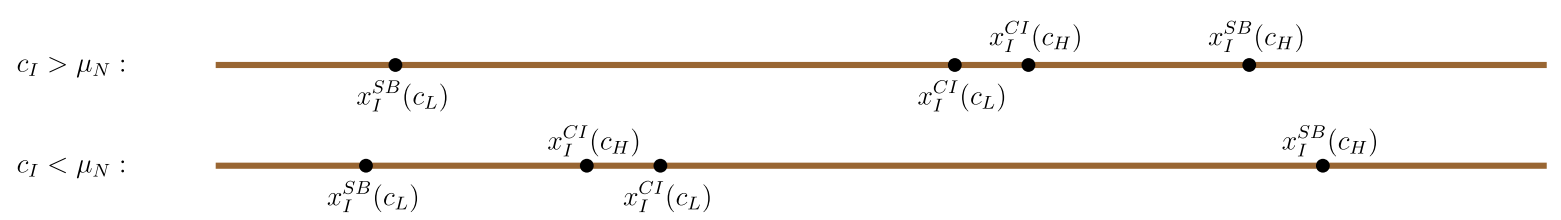

Figure 4: Efforts rankings for the incumbent in the complete information Nash equilibrium and when she is a Stackelberg leader against the different newbie types. In the upper graph we have $c_{I}>\mu_{N}$, implying $x_{I}^{C I}\left(c_{L}\right)<x_{I}^{C I}\left(c_{H}\right)$, and thus remaining ignorant moves the incumbent farther away from the Stackelberg points vis a vis both newbie types. Thus, the incumbent likes showing off. In the lower graph we have $c_{I}<\mu_{N}$, implying $x_{I}^{C I}\left(c_{L}\right)>x_{I}^{C I}\left(c_{H}\right)$, and thus remaining ignorant moves the incumbent closer to the Stackelberg points versus both newbie types. Hence, ignorance is bliss for the incumbent.

that a Stackelberg leader incumbent would overinvest in effort against an untalented newbie and underinvest against a talented one (see, for example, Dixit, 1987). The reason is that weaker opponents are deterred by greater effort levels and stronger opponents are appeased by lower ones. Furthermore, in this setting the incumbent's utility is single-peaked in her own action and is maximized when the appropriate Stackelberg effort is chosen (see Yildirim, 2005). Whether the incumbent's efforts under showing off or under ignorance lie closer to the Stackelberg efforts depends crucially on the incumbent's relative strength compared to the newbie.

The upper graph of Figure 4 depicts a situation where the incumbent is relatively weak, i.e., $c_{I}>\mu_{N}$. Notice that, in this circumstance, she exerts less effort against a talented newbie and more against an untalented one. With commitment, her ideal effort is even lower versus a talented newbie and higher in the opposite case, as shown by points $x_{I}^{S B}\left(c_{L}\right)$ and $x_{I}^{S B}\left(c_{H}\right)$ in the figure. Absent showing off, the incumbent optimally chooses a point between the full information efforts $x_{I}^{C I}\left(c_{L}\right)$ and $x_{I}^{C I}\left(c_{H}\right)$ in the figure. Since this places her further from the optimal commitment strategy regardless of the newbie's type, the incumbent benefits when the newbie shows off.

The situation where the incumbent is relatively strong, $c_{I}<\mu_{N}$, is more complicated. The ordering of the complete information efforts reverses and hence the Stackelberg actions may lie outside or inside their range. The lower graph of Figure 4 depicts the former. Clearly the incumbent's effort under ignorance is closer to her optimal commitment strategy regardless of the newbie's type. In the latter case the ranking is not as clearly visible and ignorance may only be optimal in expectation. Fortunately, the condition for ignorance to be bliss is quite simple:

Proposition 2. Consider binary types. If the incumbent is relatively talented compared to the newbie, $c_{I}<\mu_{N}$, she strictly prefers to stay ignorant about the newbie's type. If the incumbent is relatively untalented, i.e., when $c_{I}>\mu_{N}$, she prefers to obtain information about the newbie. When $c_{I}=\mu_{N}$, the incumbent is indifferent between obtaining information and staying ignorant.

Depending on the talent of the incumbent, she may both prefer the newbie to show off or to lay low. Note that the condition delineating her preferences between these two informational scenarios is equivalent to the one in Proposition 1 governing showing off: If the newbie shows off, the incumbent wants the newbie to show off; if the newbie lays low, the incumbent does not want to learn the newbie's talent either. Their interests regarding showing off are perfectly aligned. 
Now consider the general set-up. With at least three types, as we showed earlier, we may have partial separation, and thus some newbie types show off while others do not. We now study how the incumbent likes the possibility of showing off in expectation. In particular, we consider a thought experiment. Suppose that the incumbent could pick any threshold type $c_{Z} \in\left[c_{L}, c_{H}\right]$. All types with lower costs show off their types, and all types with higher costs refrain from doing so. Which threshold would she choose? Proposition 3 offers an answer:

Proposition 3. Among all possible thresholds, the threshold defined by the MIE maximizes the incumbent's expected utility.

Proposition 3 shows that, surprisingly, the threshold most preferred by the incumbent perfectly coincides with that chosen by the newbie. Thus, despite their conflict over receiving the reward, there is no conflict as regards the tactics of showing off.

\section{Cutting Down the Tall Poppies?}

Our previous analysis reveals that both parties agree about the talent threshold at which showing off improves matters. Yet societal norms are not so careful in accepting showing off behavior, regardless of talent. In Britain the distaste for showing off is described as "cutting down the tall poppies," while in Scandinavia the "Law of Jante" represents the cultural proscription against showing off. In Japan, the social obligation to conform and the consequences for those who violate this norm are described in a common proverb:

\section{"The nail that sticks out shall be hammered down"18}

On the other hand, American cultural norms, particularly in business contexts, have few such proscriptions against showing off 19 One might see this as a kind of "horses for courses" effect; that is, under some conditions, society as a whole benefits from not discouraging showing off, while in others, proscribing this behavior is better advice. If one considers expected aggregate effort as reflecting the benefits to society, our model offers a crisp answer to the question as to whether discouragements of showing off are helpful or harmful. To wit:

Theorem 2 (Norm Against Showing Off). Compared to the MIE, reducing showing off increases aggregate effort. Formally, treating the showing off threshold as a parameter, aggregate effort increases as the threshold for showing off decreases relative to the MIE threshold, i.e., when there is less showing off.

\footnotetext{
${ }^{18}$ Roku Okada, Japanese Proverbs and Proverbial Phrases, Japan Travel Bureau, Tokyo 1955, page 28.

${ }^{19}$ For example, Fineman emphasizes the importance of showing off: "The other side of the coin is this: bragging is integral to career now. You can denounce it, or you can learn how to use it to your advantage. At least, that's what I've done. Or rather, what I teach people to do. How to leverage voice and know-how and learn how to break through the noise. Or in more simple terms, redefine self-promotion to get ahead in the workplace. It's the truth of 2015, and it matters at every phase of your career." See https://www.inc.com/meredith-fineman/ showing-off-is-important.html.
} 
While Proposition 3 showed that there was complete alignment between competitors as to the optimal information disclosure regime, their interests do not align as neatly with those of a society interested in aggregate effort. In fact, the showing off choices selected by the competitors represent society's worst information disclosure regime. Any norm that discourages some newbie types from showing off increases expected aggregate effort, but if possible, society would gladly suppress showing off behavior entirely. No model can fully reflect the rich social milieu which the players inhabit. Nonetheless Theorem 2 offers useful intuitions and insights. It shows that the global norm of punishing show-offs may not be dysfunctional cultural baggage from the past in need of discarding. Instead, it could represent a sensible societal choice.

But does it also suggest that U.S. firms have somehow gotten it wrong, that they are pursuing a policy that makes them worse off? In rigid promotion systems where seniority mainly determines managerial responsibility and where contest structures are used predominantly to determine bonus payments, as often the case in Japanese firms, aggregate effort seems the most important consideration 20 Likewise in schools, where educating everyone, rather than sifting out talent, is the main goal, effort once again seems like the appropriate welfare metric.

But in other business contexts, this narrow view of welfare often seems more problematic. Businesses thrive by identifying rare talent and exploiting that for competitive advantage. This suggests that selection ought to have considerable weight in assessing the success of a business culture. Likewise, when success depends primarily on innovation, as with many Silicon Valley firms, effort cannot be the sole consideration. If selection efficiency is measured by the expected talent $c_{i}$ of the winner of the contest, a sharp result is available in the polar case, i.e., where only efficient selection matters:

Theorem 3 (Showing Off and Selection). Compared to the MIE, discouraging showing off decreases expected selection efficiency. Formally, treating the showing off threshold as a parameter, the expected talent of the winner decreases as the threshold for showing off decreases relative to the MIE threshold, i.e., when there is less showing off.

Norms that sanction showing off are conducive to increasing aggregate effort. But as Theorem 3 shows this comes at a price: it deteriorates selection efficiency. The reason is that showing off, when it happens, reveals the newbie's superior talent, which psychs out the incumbent and thus lowers her effort. However, by accentuating the competitors' differences, it also leads to greater differences in their behavior, which benefits selection efficiency. Thus, it may be that US firms are not erring by embracing a laissez-faire culture of "showing off." Rather, differences in business culture might simply reflect differing tradeoffs between effort and selection.

Behavioral reasons, such as overconfidence, might also dictate against a norm of showing off 21 When the newbie is potentially overconfident, showing off provides an additional benefit — it gives

\footnotetext{
${ }^{20}$ For example, Chlosta et al. (2014) report that, unlike in the U.S., contest structures in Japan are indeed predominantly used to determine bonus payments, suggesting that the main goal of the contest is to incentivize effort.

${ }^{21}$ Overconfidence has been shown to be an important bias affecting economic decision making. See e.g. Malmendier and Tate (2005, 2015) for evidence of overconfidence in the corporate world. Van den Steen (2004) rationalizes overconfidence in a Bayesian model.
} 
feedback to the newbie as to his true ability. Remember that only newbies that believe they are exceptional show off. An overconfident newbie who believes he is exceptional but is, in fact, quite ordinary, will be disabused of this notion when his attempts at showing off fall flat. This realization causes him to step up effort, as talent alone will not suffice. Also the incumbent increases her effort in response. This feedback comes at a cost - when the newbie is, in fact, exceptional, showing off reveals this and leads to effort reducing discouragement and complacency effects. Thus, there is a tradeoff: when the newbie is likely to be well calibrated as to his ability, a norm condemning showing off is optimal; whereas, when overconfidence is rife, a showing off culture is optimal. We show this formally for the binary case.

Proposition 4. With binary types, if the probability of an overconfident newbie is large, expected aggregate effort decreases when showing off is discouraged.

Appendix $\mathrm{G}$ adds overconfidence to the model with binary types and formalizes the intuition above about the feedback benefit of showing off.

\section{Productive Signals}

In our preceding analysis, we upheld the assumption that showing off is not directly productive but only facilitates information transmission from the newbie to the incumbent. Yet, in some situations, showing off might have a direct influence on the contest outcome. In the context of our model, this implies that showing off, or some fraction $\kappa$ of the showing off effort, translates into productive effort in the contest 22 How does this influence our results?

Recall that the main motive for (unproductive) signaling is influencing the incumbent's beliefs in such a way that she reacts with low effort in the contest. When showing off is productive, adding to productive effort at rate $\kappa$, then two new motives appear. First, since the newbie now has access to two "channels" for exerting effort, he will need to choose these optimally given his type. Second, even if showing off is not an especially efficient effort producing technology, the newbie may be motivated to employ it so as to gain a commitment advantage. If the newbie is talented, he is stronger than the incumbent, and that gives him an incentive to commit to a higher effort relative to the Nash equilibrium to soften competition; if he is untalented, he would like to commit to lower effort with the same intention (see Dixit, 1987). While commitment to a higher effort level is generally possible, commitment to a lower effort level is not, because the newbie has a second chance to choose effort and he would always increase his effort to match the complete information Nash equilibrium effort (see Lemma 1 of Yildirim, 2005). Thus, when the signal is productive, a strong newbie now has two ways to affect competition: He can signal his type through showing off and thereby alter effort responses in the second stage game. He can also use the effort produced by showing off as a commitment device, transforming the situation to

\footnotetext{
${ }^{22}$ Essentially, this implies that the newbie can invest early and late in the contest, with a potentially differing effectiveness or effective costs of effort. There are various reasons to assume the productivity or cost of effort differs across time, including learning by doing (Clark and Nilssen, 2013), recency bias (Fudenberg and Levine, 2014, 2016), or sabotage of early stage efforts (Chowdhurv and Gürtler, 2015).
} 
one resembling Stackelberg competition. Both channels can be used to psych out the incumbent. When $\kappa$ is small, the commitment channel is too expensive and our original analysis still holds. When $\kappa$ is large enough, commitment motives dominate:

Proposition 5. When types are binary and showing off produces productive effort at rate $\kappa$ per unit, then Theorems 1 to 3 hold so long as $\kappa<\bar{\kappa}=\frac{2}{3}$. In particular, a norm against showing off yields higher aggregate effort, while selection is inhibited.

The threshold where productive effort starts affecting our results highlights the relative importance of the two new factors introduced by this extension. Notice that, if the allocation of productive effort across channels were the main driver, then the relevant threshold would be $\kappa=1$. When $\kappa>1$, showing off is the more efficient effort producing technology whereas when $\kappa<1$, it is inefficient. Instead, the critical value of $\kappa$ represents a threshold for commitment forces to come into play. In a sense, $\kappa$ characterizes the expense of a commitment strategy - commitment is cheaper for higher values of $\kappa$. Since no such commitment was present in the baseline model, it then follows that, so long as commitment via showing off remains unattractive, the strategic considerations of the two parties are unchanged. By contrast, when commitment via signaling is sufficiently cost effective, the (talented) newbie avails herself of this strategy and the game becomes, in effect, sequential with the newbie having the first move in generating effort via showing off 23

\section{Conclusion}

The Cambridge dictionary defines showing off as "to behave in a way that is intended to attract attention or admiration, and that other people often find annoying."24 This definition, especially the latter part, is in line with social norms around the globe, for example the Tall Poppy Syndrome known in large parts of the English speaking world or the Law of Jante known in Nordic countries. At the same time, in many business environments, as for example in Silicon Valley, no such proscriptions exist, and showing off one's talent is often even well regarded. In this paper we study the economics of showing off and laying low and its consequences. We augment a standard contest model by allowing a new competitor (newbie) to transmit information through showing off to an established competitor (incumbent). Our analysis reveals that the desirability of showing off is indeed a question of horses for courses.

Showing off allows a contestant to influence the beliefs of his contender. We found that, unlike in standard signaling games à la Spence (1973), incentives to signal one's type through showing off can run in either direction: a weak contender might want to mimic a strong one, and a strong

\footnotetext{
${ }^{23}$ Note that giving the incumbent a chance to "show off" as well, i.e., to expend productive effort at rate $\kappa$ ahead of the contest does not change our findings qualitatively when $\kappa$ is sufficiently low. The reason is that the incumbent benefits from the newbie's showing off and prefers to use the information the newbie provides him with instead of tying her hands by pre-committing to a high effort level.

${ }^{24}$ https://dictionary.cambridge.org/dictionary/english/show-off. Interestingly the American definition merely states: "to do something to attract attention to yourself" and thus does not come with a negative connotation.
} 
contender might want to mimic a weak contender, in both cases with the aim to decrease the fierceness of ensuing competition. But while meager talent is easily mimicked, it is hard to mimic someone exceptional, and hence only the exceptional will successfully engage in showing off.

While the newbie decides whether to show off or lay low according to his liking, the incumbent may not have a choice in this matter. Surprisingly, though, the incumbent is well-served by the showing off behavior of the newbie. While showing off aims at psyching out the opponent, who reacts by reducing effort, it also decreases the general fierceness of competition. When showing off happens, it leads to an overall reduction in effort. In this sense, pre-conflict showing off behavior can be seen as a form of collusion, benefitting both competitors. Our analysis thus offers a rationale for the emergence of norms against showing off in circumstances where societies' concerns lie with aggregate effort.

On the other hand, in settings where selection of the most talented is paramount, a norm against showing off is not advisable. Showing off tends to accentuate competitors' differences and thus helps selecting the best. Because innovative firms, like startups, rely exactly on that, our results shed some light on why a norm against showing off seems absent from Silicon Valley business etiquette. 


\section{Appendix}

\section{A Preliminaries: Equilibrium under Full- and Asymmetric Infor- mation}

In this section we derive equilibrium efforts as well as utility when all types of newbies from the interval $\left[c_{L}, c_{Z}\right]$ reveal their types, while newbies in $\left[c_{Z}, c_{H}\right]$ do not reveal their types. In both cases, the incumbent updates her beliefs accordingly. Note that this analysis nests the full information case when $c_{Z}=c_{H}$ (i.e., all newbies reveal their types) as well as the no information case when $c_{Z}=c_{L}$ (i.e., no newbie reveals his type).

Lemma 1. Let $c_{N}$ be distributed according to some distribution $F\left(c_{N}\right)$ over the interval $\left[c_{L}, c_{H}\right]$ with strictly positive density $f\left(c_{N}\right)$. Moreover, let $c_{H} \leq 4 c_{L}$. Assume all newbie types $c_{N}<c_{Z}$ show off their type, while all others lay low and pool. The subgame in which the incumbent does not receive a signal has a unique equilibrium, which is in pure strategies:

$$
x_{I}^{A I}=\frac{\left(\int_{c_{Z}}^{c_{H}} \sqrt{c_{N}} d F\left(c_{N}\right)\right)^{2}}{\left(c_{I}\left(1-F\left(c_{Z}\right)\right)+\int_{c_{Z}}^{c_{H}} c_{N} d F\left(c_{N}\right)\right)^{2}}>0 .
$$

and

$$
x_{N}^{A I}=\sqrt{\frac{x_{I}^{A I}}{c_{N}}}-x_{I}^{A I}>0
$$

Ex-post, the corresponding equilibrium utility of the incumbent is

$$
\pi_{I}^{A I}=\frac{x_{I}^{A I}}{x_{I}^{A I}+x_{N}^{A I}}-c_{I} x_{I}^{A I}=\sqrt{c_{N} x_{I}^{A I}}-c_{I} x_{I}^{A I} .
$$

In case the incumbent learns the newbie's type, the subgame equilibrium follows from the equilibrium characterization under complete information (see Nt, 1999):

$$
x_{i}^{C I}=\frac{c_{j}}{\left(c_{I}+c_{N}\right)^{2}}, \quad X^{C I} \equiv x_{I}^{C I}+x_{N}^{C I}=\frac{1}{c_{I}+c_{N}}, \quad \pi_{i}^{C I}=\frac{c_{j}^{2}}{\left(c_{I}+c_{N}\right)^{2}}
$$

It is easily verified that the incumbent will invest more against a low-cost opponent $c_{L}$ than against a high-cost one $c_{H}$ if and only if $c_{I}<\sqrt{c_{H} c_{L}}$.

Ex-ante the utility of the incumbent when all newbie types in the interval $\left[c_{L}, c_{Z}\right]$ signal and thus reveal their types equals

$$
E \pi_{I}=\int_{c_{L}}^{c_{Z}} \frac{c_{N}^{2}}{\left(c_{N}+c_{I}\right)^{2}} d F\left(c_{N}\right)+\frac{\left(\int_{c_{Z}}^{c_{H}} \sqrt{c_{N}} d F\left(c_{N}\right)\right)^{2} \int_{c_{Z}}^{c_{H}} c_{N} d F\left(c_{N}\right)}{\left(c_{I}\left(1-F\left(c_{Z}\right)\right)+\int_{c_{Z}}^{c_{H}} c_{N} d F\left(c_{N}\right)\right)^{2}}
$$


Similarly, expected aggregate effort is equal to

$$
E X=\int_{c_{L}}^{c_{Z}} \frac{1}{c_{N}+c_{I}} d F\left(c_{N}\right)+\frac{\int_{c_{Z}}^{c_{H}} \sqrt{c_{N}} d F\left(c_{N}\right) \int_{c_{Z}}^{c_{H}} \frac{1}{\sqrt{c_{N}}} d F\left(c_{N}\right)}{\left(c_{I}\left(1-F\left(c_{Z}\right)\right)+\int_{c_{Z}}^{c_{H}} c_{N} d F\left(c_{N}\right)\right)}
$$

Proof. The incomplete information (sub-)game can be solved easiest by taking the FOC of the incumbent

$$
\frac{1}{1-F\left(c_{Z}\right)} \int_{c_{Z}}^{c_{H}} \frac{x_{N}\left(c_{N}\right)}{\left(x_{I}+x_{N}\left(c_{N}\right)\right)^{2}} d F\left(c_{N}\right)=c_{I}
$$

and then inserting the best-response of all newbie types, $B R_{N}\left(x_{I} ; c_{N}\right)=\max \left\{0, \sqrt{\frac{x_{I}}{c_{N}}}-x_{I}\right\}=$ $\sqrt{\frac{x_{I}}{c_{N}}}-x_{I}$ when $4 c_{L} \geq c_{H}$, which is guaranteed by Assumption 1, This yields

$$
\begin{aligned}
& \frac{1}{1-F\left(c_{Z}\right)} \int_{c_{Z}}^{c_{H}} \frac{\sqrt{\frac{x_{I}}{c_{N}}}-x_{I}}{\left(x_{I}+\sqrt{\frac{x_{I}}{c_{N}}}-x_{I}\right)^{2}} d F\left(c_{N}\right)=c_{I} \Leftrightarrow \int_{c_{Z}}^{c_{H}} c_{N}\left(\frac{1}{\sqrt{x_{I} c_{N}}}-1\right) d F\left(c_{N}\right)=c_{I}\left(1-F\left(c_{Z}\right)\right) \\
& \Leftrightarrow \frac{\int_{c_{Z}}^{c_{H}} \sqrt{c_{N}} d F\left(c_{N}\right)}{\sqrt{x_{I}}}=c_{I}\left(1-F\left(c_{Z}\right)\right)+\int_{c_{Z}}^{c_{H}} c_{N} d F\left(c_{N}\right) \Leftrightarrow x_{I}^{A I}\left(c_{Z}\right)=\frac{\left(\int_{c_{Z}}^{c_{H}} \sqrt{c_{N}} d F\left(c_{N}\right)\right)^{2}}{\left(c_{I}\left(1-F\left(c_{Z}\right)\right)+\int_{c_{Z}}^{c_{H}} c_{N} d F\left(c_{N}\right)\right)^{2}} .
\end{aligned}
$$

The corresponding SOC is fulfilled, as

$$
-\frac{1}{1-F\left(c_{Z}\right)} \int_{c_{Z}}^{c_{H}} \frac{x_{N}\left(c_{N}\right)}{\left(x_{I}+x_{N}\left(c_{N}\right)\right)^{3}} d F\left(c_{N}\right)<0
$$

and thus the FOC characterize a global utility maximum. Similar steps establish a global maximum for the newbie. Expected utility and expected aggregate effort follow directly from the equilibrium effort levels.

\section{B Proof of Theorem 1: Showing Off}

The proof proceeds in several steps. First we show that separation is not possible for types that are less talented than the incumbent. Then we characterize the threshold type of the maximally informative equilibrium. Finally we derive the equilibrium signaling cost function and show that there are no profitable deviations.

Signaling utility. A player's maximized utility, when his opponent believes him to be of type $c^{\prime}$, while in fact he is of type $c_{N}$, is

$$
\pi_{N}\left(c^{\prime} ; c_{N}\right)=\frac{B R_{N}\left(x_{I}\left(c^{\prime}\right) ; c_{N}\right)}{B R_{N}\left(x_{I}\left(c^{\prime}\right) ; c_{N}\right)+x_{I}\left(c^{\prime}\right)}-c_{N} B R_{N}\left(x_{I}\left(c^{\prime}\right) ; c_{N}\right)
$$

where $B R_{N}\left(x_{I}\left(c^{\prime}\right) ; c_{N}\right)$ is the best response effort choice of the newbie against the effort $x_{I}\left(c^{\prime}\right)$ of the incumbent who believes to be facing an opponent with marginal cost $c^{\prime}$. Because $B R_{N}\left(x_{I} ; c_{N}\right)=$ 
$\sqrt{\frac{x_{I}}{c_{N}}}-x_{I}$ and $x_{I}\left(c^{\prime}\right)=\frac{c^{\prime}}{\left(c^{\prime}+c_{I}\right)^{2}}$, this simplifies to

$$
\pi_{N}\left(c^{\prime} ; c_{N}\right)=\frac{\left(c_{I}-\sqrt{c_{N} c^{\prime}}+c^{\prime}\right)^{2}}{\left(c_{I}+c^{\prime}\right)^{2}}
$$

Taking into account the cost to signal to be of type $c^{\prime}$, which equals $c_{N} s\left(c^{\prime}\right)$, we get

$$
\pi_{N}^{S}\left(c^{\prime} ; c_{N}\right)=\frac{\left(c_{I}-\sqrt{c_{N} c^{\prime}}+c^{\prime}\right)^{2}}{\left(c_{I}+c^{\prime}\right)^{2}}-c_{N} s\left(c^{\prime}\right)
$$

Untalented newbies and the impossibility of separation. In the first part of the proof we show that, given two newbie types $c_{N}^{\prime}$ and $c_{N}^{\prime \prime}$, separation is never possible when both are relatively untalented. In particular, we prove this by showing that for any two $c_{N}^{\prime}$ and $c_{N}^{\prime \prime}$, whenever $c_{I}<\sqrt{c_{N}^{\prime} c_{N}^{\prime \prime}}$, it is not possible to find a pair of signals that reveal the types without the incentives to mimic.

Lemma 2. Let there be a range of values $\mathcal{S}^{\prime}=\left[\underline{c}_{N}, \bar{c}_{N}\right]$ such that $\underline{c}_{N}<\bar{c}_{N}$ and $c_{I} \leq \underline{c}_{N}$. Then, a separating equilibrium among $c_{N} \in \mathcal{S}^{\prime}$ does not exist.

Proof. Take two types from $\mathcal{S}^{\prime}, c_{N}^{\prime}$ and $c_{N}^{\prime \prime}, c_{N}^{\prime}<c_{N}^{\prime \prime}$. Using (2), we can write the incentive constraints as follows:

$$
\begin{array}{ll}
c_{N}^{\prime}: & \pi_{N}^{S}\left(c_{N}^{\prime} ; c_{N}^{\prime}\right) \geq \pi_{N}^{S}\left(c_{N}^{\prime \prime} ; c_{N}^{\prime}\right) \\
c_{N}^{\prime \prime}: & \pi_{N}^{S}\left(c_{N}^{\prime \prime} ; c_{N}^{\prime \prime}\right) \geq \pi_{N}^{S}\left(c_{N}^{\prime} ; c_{N}^{\prime \prime}\right)
\end{array}
$$

Rewriting these constraints using the specific formulas yields

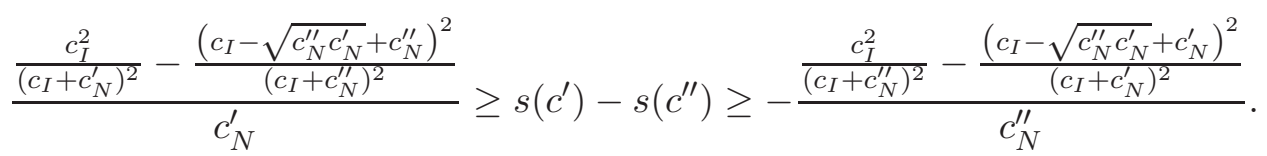

For separation to be possible it is necessary and sufficient that

$$
\frac{\frac{c_{I}^{2}}{\left(c_{I}+c_{N}^{\prime}\right)^{2}}-\frac{\left(c_{I}-\sqrt{c_{N}^{\prime \prime} c_{N}^{\prime}}+c_{N}^{\prime \prime}\right)^{2}}{\left(c_{I}+c_{N}^{\prime \prime}\right)^{2}}}{c_{N}^{\prime}}>-\frac{\frac{c_{I}^{2}}{\left(c_{I}+c_{N}^{\prime \prime}\right)^{2}}-\frac{\left(c_{I}-\sqrt{c_{N}^{\prime \prime} c_{N}^{\prime}}+c_{N}^{\prime}\right)^{2}}{\left(c_{I}+c_{N}^{\prime}\right)^{2}}}{c_{N}^{\prime \prime}},
$$

which is the case if and only if $c_{I}>\sqrt{c_{N}^{\prime} c_{N}^{\prime \prime}}$. Because $c_{I}<\underline{c}_{N}$ implies $c_{I}<\sqrt{c_{N}^{\prime} c_{N}^{\prime \prime}}$ for all $c_{N}^{\prime}, c_{N}^{\prime \prime} \in \mathcal{S}^{\prime}$, separation is not possible for any $c_{N} \in \mathcal{S}^{\prime}$.

Proposition 1 studying showing off with a binary type distribution follows directly from the last paragraph of the proof of Lemma 2 .

Corollary 1. Consider binary types. A showing off equilibrium, where the newbie's type is completely revealed exists if and only if $c_{I}>\sqrt{c_{L} c_{H}}$.

Note that a perfect Bayesian pooling equilibrium always exists. Invoking the Cho and Kreps (1987) intuitive criterion eliminates the pooling equilibrium when $c_{I}>\sqrt{c_{H} c_{L}}$. Also note that for 
$c_{I}=\sqrt{c_{H} c_{L}}$ all parties are indifferent regarding showing off, as an incumbent chooses the same effort against a talented and untalented newbie.

Maximally informative equilibria. Returning to the general case, Lemma 2 implies that only partial separation can be possible whenever $c_{I}<c_{H}$. Thus, only types below some threshold $c_{Z}$ may be able to signal their types in equilibrium. Before continuing, we now formally define the MIE:

Definition 2 (Maximally Informative equilibrium, MIE). Let $\tilde{c}_{N} \in \mathcal{S}_{N}$ be the greatest possible threshold type such that all $c_{N}<\tilde{c}_{N}$ show off and separate while all $c_{N} \geq \tilde{c}_{N}$ lay low and pool, given $\mathcal{S}_{N}$ and $F\left(c_{N}\right)$. A threshold equilibrium with $c_{Z}=\tilde{c}_{N}$ is called a maximally informative equilibrium.

To study incentives we need to determine equilibrium effort under incomplete information. From Lemma 1 it follows that the incumbent, when he only knows that $c_{N} \in\left[c_{Z}, c_{H}\right]$, chooses the asymmetric information effort in the pooling equilibrium:

$$
x_{I}^{A I}\left(c_{Z}\right)=\frac{\left(\int_{c_{Z}}^{c_{H}} \sqrt{c_{N}} d F\left(c_{N}\right)\right)^{2}}{\left(c_{I}\left(1-F\left(c_{Z}\right)\right)+\int_{c_{Z}}^{c_{H}} c_{N} d F\left(c_{N}\right)\right)^{2}}=\frac{\left(E\left[\sqrt{c_{N}} \mid c_{N} \geq c_{Z}\right]\right)^{2}}{\left(c_{I}+E\left[c_{N} \mid c_{N} \geq c_{Z}\right]\right)^{2}}
$$

Then the following is true:

Lemma 3. In any pooling equilibrium,

$$
\min \left\{\frac{c_{H}}{\left(c_{H}+c_{I}\right)^{2}}, \frac{c_{Z}}{\left(c_{Z}+c_{I}\right)^{2}}\right\}<x_{I}^{A I}\left(c_{Z}\right)<\frac{1}{4 c_{I}} .
$$

The effort in the pooling equilibrium cannot be greater than the greatest effort expended under complete information against the same types, and it cannot be lower than the lowest effort expended under complete information against the same types.

Proof. We first prove the upper boundary. From Jensen's inequality it follows that $\sqrt{E\left[c_{N} \mid c_{N} \geq c_{Z}\right]}>$ $E\left[\sqrt{c_{N}} \mid c_{N} \geq c_{Z}\right]$. We can then replace the latter by the former in the formula determining $A$ 's strategy and get

$$
\frac{E\left[c_{N} \mid c_{N} \geq c_{Z}\right]}{\left(c_{I}+E\left[c_{N} \mid c_{N} \geq c_{Z}\right]\right)^{2}}>x_{I}^{A I}\left(c_{Z}\right)
$$

This expression is now greater than $x_{I}^{A I}\left(c_{Z}\right)$ and maximized when $E\left[c_{N} \mid c_{N} \geq c_{Z}\right]=c_{I}$. In this case

$$
\frac{c_{I}}{\left(c_{I}+c_{I}\right)^{2}}=\frac{1}{4 c_{I}}>x_{I}^{A I}\left(c_{Z}\right)
$$

proving the first half.

To prove the second half look at the first-order condition of the incumbent and then plug in 
the best response of the newbie:

$$
E\left[\sqrt{\frac{c_{N}}{x_{I}}}-c_{I}-c_{N} \mid c_{N} \geq c_{Z}\right]=0
$$

Assume without loss of generality that $\frac{c_{H}}{\left(c_{H}+c_{I}\right)^{2}}<\frac{c_{Z}}{\left(c_{Z}+c_{I}\right)^{2}} \Leftrightarrow \frac{c_{I}^{2}}{c_{H}}<c_{Z}$ and let $x_{I}=\frac{c_{H}}{\left(c_{I}+c_{H}\right)^{2}}$, that is the smallest effort chosen under complete information. Then we get, after some simplifications,

$$
E\left[\left(\frac{\sqrt{c_{N}}\left(c_{I}+c_{H}\right)}{\sqrt{c_{H}}}-c_{I}-c_{N}\right) \mid c_{N} \geq c_{Z}\right]=: E\left[\zeta\left(c_{N}, c_{H}, c_{I}\right) \mid c_{N} \geq c_{Z}\right]=0
$$

Note that $\zeta\left(c_{N}, c_{H}, c_{I}\right)$ has two roots in $c_{N}$, when $c_{N}=c_{H}$ and when $c_{N}=\frac{c_{I}^{2}}{c_{H}}$, and that

$$
\left.\frac{\partial \zeta\left(c_{N}, c_{H}, c_{I}\right)}{\partial c_{N}}\right|_{c_{N}=c_{H}}<0
$$

implying that as $c_{N}$ gets smaller, $\zeta$ increases at this point. Consequently, for (3) to be zero, we need that some types $c_{N}<\frac{c_{I}^{2}}{c_{H}}$ occur with positive probability, but this contradicts $\frac{c_{I}^{2}}{c_{H}}<c_{Z}$. Thus, evaluated at $x_{I}=\frac{c_{H}}{\left(c_{I}+c_{H}\right)^{2}}$, the incumbent's FOC is positive. Together with concavity of his utility function, this implies that in equilibrium $x_{I}^{A I}\left(c_{Z}\right)>\frac{c_{H}}{\left(c_{I}+c_{H}\right)^{2}}$, and thus it proves the second part of the lemma.

The next lemma is crucial to prove existence and uniqueness of the MIE.

Lemma 4. If $c_{I} \geq \mu_{N}=\sqrt{c_{L} c_{H}}, x_{I}^{A I}\left(c_{Z}\right)$ and $x_{I}^{C I}\left(c_{Z}\right)$ intersect exactly twice on $c_{Z} \in\left[c_{L}, c_{H}\right]$, once at some $c_{Z}=\tilde{c}_{N}<c_{I}$ and once at $c_{Z}=c_{H}$. If $c_{I}<\mu_{N}$, there could be both one or two intersections, depending on the details of the distribution $F\left(c_{N}\right)$.

Proof. Define

$$
\Delta x_{I}\left(c_{Z}\right) \equiv x_{I}^{A I}\left(c_{Z}\right)-x_{I}^{C I}\left(c_{Z}\right)
$$

First note that

$$
\lim _{c_{Z} \rightarrow c_{H}} \Delta x_{I}\left(c_{Z}\right)=0
$$

which can be shown easily by repeatedly applying L'Hôpital's rule to $x_{I}^{A I}\left(c_{Z}\right)$. Hence, this is the first intersection of $x_{I}^{A I}\left(c_{Z}\right)$ and $x_{I}^{C I}\left(c_{Z}\right)$. Second, note that

$$
\Delta x_{I}\left(c_{I}\right)=x_{I}^{A I}\left(c_{I}\right)-\frac{c_{I}}{\left(c_{I}+c_{I}\right)^{2}}=x_{I}^{A I}\left(c_{I}\right)-\frac{1}{4 c_{I}}<0
$$

by Lemma 3 . Moreover,

$$
\Delta x_{I}\left(\frac{c_{I}^{2}}{c_{H}}\right)=x_{I}^{A I}\left(\frac{c_{I}^{2}}{c_{H}}\right)-\frac{c_{I}^{2}}{c_{H}\left(c_{I}+\frac{c_{I}^{2}}{c_{H}}\right)^{2}}=x_{I}^{A I}\left(\frac{c_{I}^{2}}{c_{H}}\right)-\frac{c_{H}}{\left(c_{I}+c_{H}\right)^{2}}>0
$$

Hence, by continuity, there must be $\tilde{c}_{N} \in\left(\frac{c_{I}^{2}}{c_{H}}, c_{I}\right)$ such that $\Delta x_{I}\left(\tilde{c}_{N}\right)=0$, proving existence of 
the second intersection for $c_{I}>\mu_{N}$. Note that when $\frac{c_{I}^{2}}{c_{H}}<c_{L} \Leftrightarrow c_{I}<\sqrt{c_{L} c_{H}}=\mu_{N}, \tilde{c}_{N}$ might be smaller than $c_{L}$, which is why there might be only one intersection on $\left[c_{L}, c_{H}\right]$ in this case.

Could there be another $c_{Z} \in\left(\tilde{c}_{N}, c_{H}\right)$ such that $x_{I}^{A I}=x_{I}^{C I}$ ? Next we show that this is not possible. First note that $x_{I}^{C I}$ is strictly concave, increasing on $\left[c_{L}, c_{I}\right)$ and decreasing on $\left(c_{I}, c_{H}\right]$. To see how $x_{I}^{A I}$ changes with $c_{Z}$ we differentiate it:

$$
\begin{aligned}
\frac{\partial x_{I}^{A I}}{\partial c_{Z}} & =\frac{2 f\left(c_{Z}\right)\left(\int_{c_{Z}}^{c_{H}} \sqrt{c_{N}} f\left(c_{N}\right) d c_{N}\right)}{\left(c_{I} \int_{c_{Z}}^{c_{H}} f\left(c_{N}\right) d c_{N}+\int_{c_{Z}}^{c_{H}} c_{N} f\left(c_{N}\right) d c_{N}\right)^{3}} \\
& \times\left[\left(c_{I}+c_{Z}\right) \int_{c_{Z}}^{c_{H}} \sqrt{c_{N}} f\left(c_{N}\right) d c_{N}-\sqrt{c_{Z}}\left(\int_{c_{Z}}^{c_{H}} c_{N} f\left(c_{N}\right) d c_{N}+c_{I}\left(1-F\left(c_{Z}\right)\right)\right)\right]
\end{aligned}
$$

We can easily verify that the sign of the derivative turns on the sign of the squared brackets, which turns on $x_{I}^{A I}-x_{I}^{C I}$. Thus,

$$
\operatorname{Sign}\left[\frac{\partial x_{I}^{A I}}{\partial c_{Z}}\right]=\operatorname{Sign}\left[x_{I}^{A I}-x_{I}^{C I}\right]
$$

which implies that at $\tilde{c}_{N}$ the derivative is zero. Since $x_{I}^{C I}$ is increasing on $\left[c_{L}, c_{I}\right], x_{I}^{A I}$ must be decreasing on some interval $\left(\tilde{c}_{N}, c_{Z}^{\prime}\right], c_{Z}^{\prime}>c_{I}$, and it can only increase again after $x_{I}^{A I}=x_{I}^{C I}$ once more. If this were too happen for some $c_{Z}^{\prime}<c_{H}, x_{I}^{A I}$ were increasing on $\left(c_{Z}^{\prime}, c_{H}\right]$, because $x_{I}^{C I}$ is still strictly decreasing. But this would imply that when $c_{Z}=c_{H}, x_{I}^{A I}>x_{I}^{C I}$, which cannot be the case. Hence, $c_{Z}^{\prime}$ cannot be smaller than $c_{H}$, implying $x_{I}^{A I}$ decreases on $\left(\tilde{c}_{N}, c_{H}\right)$, and there cannot be $c_{Z} \in\left(\tilde{c}_{N}, c_{H}\right)$ such that $x_{I}^{A I}=x_{I}^{C I}$.

Finally, note that it must be that $x_{I}^{A I}>x_{I}^{C I}$ if $c_{Z} \in\left(c_{Z}^{\prime}, \tilde{c}_{N}\right)$ for some $c_{Z}^{\prime}<\tilde{c}_{N}$. Could it be the case that there exists $c_{Z}^{\prime}>c_{L}$ such that both efforts intersect again? Note that $x_{I}^{C I}$ increases on $\left[c_{L}, \tilde{c}_{Z}\right]$ and is concave. This implies that if there is another intersection, $x_{I}^{A I}$ must be steeper than $x_{I}^{C I}$ at this point and it thus must have a strictly positive slope. However, such an intersection then implies that $x_{I}^{A I}$ cannot be differentiable at the intersection, because we know that the derivative must be zero when $x_{I}^{A I}=x_{I}^{C I}$. However, it is differentiable. Thus, this intersection cannot exist. Consequently, $x_{I}^{A I}\left(c_{Z}\right)=x_{I}^{C I}\left(c_{Z}\right)$ on $\left[c_{L}, c_{H}\right]$ exactly twice when $c_{I} \geq \mu_{N}$ and once or twice else.

Now we return to the equilibrium analysis. In the MIE, the threshold type needs to be indifferent between signaling and pooling. In a maximally informative equilibrium, the greatest share of newbies possible signals, and thus the threshold type $\tilde{c}_{N}$ incurs no signaling costs. Since he only reacts optimally to the incumbent's effort, the incumbent needs to choose identical effort against the threshold type whether he signals his type or pools, $\Delta x_{I}\left(\tilde{c}_{N}\right)=0$. From Lemma 2 it follows that the threshold must be lower than $c_{I}$. From Lemma 4 it follows that if $c_{I} \geq \mu_{N}$, a unique threshold type exists for which this is the case. 
Equilibrium showing off. To find the signal cost function $s\left(c^{\prime}\right)$ for which truth-telling is strictly optimal, we take the first order condition of $\pi_{N}^{S}\left(c^{\prime} ; c_{N}\right)$ in (2) with respect to the stated type $c^{\prime}$ :

$$
-\frac{2\left(c_{I}-\sqrt{c_{N} c^{\prime}}+c^{\prime}\right)^{2}}{\left(c_{I}+c^{\prime}\right)^{3}}+\frac{2\left(1-\frac{c_{N}}{2 \sqrt{c_{N} c^{\prime}}}\right)\left(c_{I}-\sqrt{c_{N} c^{\prime}}+c^{\prime}\right)}{\left(c_{I}+c^{\prime}\right)^{2}}-c_{N} s^{\prime}\left(c^{\prime}\right)
$$

We are searching for a function for which utility is maximized when $c^{\prime}=c_{N}$. Thus, now let $c^{\prime}=c_{N}$ and set the derivative equal to zero to find the local extrema:

$$
\frac{c_{I}\left(c_{N}-c_{I}\right)}{\left(c_{I}+c_{N}\right)^{3}}-c_{N} s^{\prime}\left(c_{N}\right)=0
$$

This is a differential equation that can easily be solved. The general solution for $s\left(c^{\prime}\right)$ is

$$
\tilde{s}\left(c^{\prime}\right)=K-\frac{2 c_{I}+c^{\prime}}{\left(c_{I}+c^{\prime}\right)^{2}}+\frac{\ln \left(\frac{c_{I}+c^{\prime}}{c^{\prime}}\right)}{c_{I}}
$$

where $K$ is a constant. Note that the least attractive type $c^{\prime}$ one might signal, given $\tilde{c}_{N} \leq c_{I}$, is $c^{\prime}=\tilde{c}_{N}$, because that is the type closest to $c_{I}$ and hence $A$ will be most aggressive against this type. Therefore, it is sensible to demand that $\tilde{c}_{N}$ does not need to signal at all, $s\left(\tilde{c}_{N}\right)=0$. This implies

$$
K=\frac{2 c_{I}+\tilde{c}_{N}}{\left(c_{I}+\tilde{c}_{N}\right)^{2}}-\frac{\ln \left(\frac{c_{I}+\tilde{c}_{N}}{\tilde{c}_{N}}\right)}{c_{I}}
$$

and therefore equilibrium showing off follows

$$
s^{*}\left(c^{\prime}\right)=\frac{\ln \left(\frac{\tilde{c}_{N}\left(c_{I}+c^{\prime}\right)}{c^{\prime}\left(c_{I}+\tilde{c}_{N}\right)}\right)}{c_{I}}+\frac{2 c_{I}+\tilde{c}_{N}}{\left(c_{I}+\tilde{c}_{N}\right)^{2}}-\frac{2 c_{I}+c^{\prime}}{\left(c_{I}+c^{\prime}\right)^{2}} .
$$

It remains to verify that $s^{*}\left(c^{\prime}\right)$ really implements a separating equilibrium. Take (2) and replace $s\left(c^{\prime}\right)$ by $s^{*}\left(c^{\prime}\right)$ :

$$
\pi_{N}^{*}\left(c^{\prime} ; c_{N}\right)=\frac{\left(c_{I}-\sqrt{c_{N} c^{\prime}}+c^{\prime}\right)^{2}}{\left(c_{I}+c^{\prime}\right)^{2}}-c_{N}\left(\frac{\ln \left(\frac{\tilde{c}_{N}\left(c_{I}+c^{\prime}\right)}{c^{\prime}\left(c_{I}+\tilde{c}_{N}\right)}\right)}{c_{I}}+\frac{2 c_{I}+\tilde{c}_{N}}{\left(c_{I}+\tilde{c}_{N}\right)^{2}}-\frac{2 c_{I}+c^{\prime}}{\left(c_{I}+c^{\prime}\right)^{2}}\right)
$$

Maximizing this with respect to the claimed type $c^{\prime}$, we get the first-order condition

$$
\frac{\partial \pi^{*}\left(c^{\prime} ; c_{N}\right)}{\partial c^{\prime}}=-\frac{c_{N}^{2}\left(c^{\prime}-c_{I}\right)\left(\sqrt{c_{N} c^{\prime}}-c^{\prime}\right)}{\left(c_{I}+c^{\prime}\right)^{2}\left(c_{N} c^{\prime}\right)^{3 / 2}}=0 .
$$

This equation has two roots, one at $c^{\prime}=c_{I}$ and one at $c^{\prime}=c_{N}$. The second-order conditions are

$$
\left.\frac{\partial^{2} \pi^{*}\left(c^{\prime} ; c_{N}\right)}{\partial c^{\prime 2}}\right|_{c^{\prime}=c_{I}}=\frac{c_{N}\left(c_{I}-\sqrt{c_{I} c_{N}}\right)}{4 \sqrt{c_{I}^{7} c_{N}}}>0 \forall c_{N} \in\left[c_{L}, \tilde{c}_{N}\right]
$$


and

$$
\left.\frac{\partial^{2} \pi^{*}\left(c^{\prime} ; c_{N}\right)}{\partial c^{\prime 2}}\right|_{c^{\prime}=c_{N}}=\frac{c_{N}-c_{I}}{2 c_{N}\left(c_{I}+c_{N}\right)^{2}}<0 \forall c_{N} \in\left[c_{L}, \tilde{c}_{N}\right]
$$

respectively. Thus, the latter, where $c^{\prime}=c_{N}$, is indeed a local maximum as $\tilde{c}_{N}<c_{I}$, while $c^{\prime}=c_{I}$ is a local minimum. Moreover, since there are no other roots of the first-order condition, we can also exclude corner-solutions, because the utility minimum occurs when $c^{\prime}=c_{I}$, which is not within the range of potential types, implying $\pi_{N}^{*}\left(c^{\prime} ; c_{N}\right)$ is strictly quasi-concave in $c^{\prime}$ on $\left[c_{L}, \tilde{c}_{N}\right]$. Could a talented newbie benefit from deviating by pretending to have $c_{N}>\tilde{c}_{N}$ ? No, because this would give him the exact same utility he would get from pretending to have type $\tilde{c}_{N}$ by definition of this type, because the incumbent's effort and the cost from showing off would be just the same. Hence, given $s^{*}\left(c^{\prime}\right)$, truthfully revealing one's type is the unique best strategy for all types $\left[c_{L}, \tilde{c}_{N}\right]$.

Incentive compatibility for pooling newbies. Next we look at incentive compatibility for the pooling newbie types $\left[\tilde{c}_{N}, c_{H}\right]$. We need to assure that none of them has an incentive to mimic any $c_{N}<\tilde{c}_{N}$. The benefit from mimicking is that $A$ competes less fiercely against the more efficient types than in the pooling equilibrium, which is beneficial. Consider the incentives of some $c_{N}>\tilde{c}_{N}$ to mimic some $c_{N}^{\prime}<\tilde{c}_{N}$. The utility he gets from pooling is

$$
\pi_{N}^{P o o l}=\frac{\sqrt{\frac{x_{I}^{A I}}{c_{N}}}-x_{I}^{A I}}{\sqrt{\frac{x_{I}^{A I}}{c_{N}}}-x_{I}^{A I}+x_{I}^{A I}}-c_{N}\left(\sqrt{\frac{x_{I}^{A I}}{c_{N}}}-x_{I}^{A I}\right)=\left(1-\sqrt{c_{N} x_{I}^{A I}}\right)^{2}
$$

Hence, the maximum willingness to spend on a signal that mimics some type $c_{N}^{\prime}<\tilde{c}_{N}$ is

$$
I\left(c_{N}^{\prime} ; c_{N}\right)=\frac{\frac{\left(c_{I}-\sqrt{c_{N} c_{N}^{\prime}}+c_{N}^{\prime}\right.}{\left(_{c}+c_{N}^{\prime}\right)^{2}}-\left(1-\sqrt{c_{N} x_{I}^{A I}}\right)^{2}}{c_{N}} .
$$

We know that the marginal type $\tilde{c}_{N}$ has no incentive to mimic any other $c_{N}^{\prime}<\tilde{c}_{N}$, because he is indifferent between revealing his type and pooling, and given $s^{*}\left(c^{\prime}\right)$ he would choose $c^{\prime}=\tilde{c}_{N}$. If we can show that the incentives to mimic are decreasing in $c_{N}$, that is types with higher marginal cost have less incentives to mimic a given $c_{N}^{\prime}$ than types with lower marginal cost, then the fact that $\tilde{c}_{N}$ is indifferent is sufficient to prove that nobody with greater cost has an incentive to deviate either.

Lemma 5. The maximum willingness to spend on a signal to mimic some $c_{N}^{\prime}$ is decreasing in $c_{N}$ if

$$
x_{I}^{A I}\left(\tilde{c}_{N}\right)>\frac{c_{N}^{\prime}}{\left(c_{I}+c_{N}^{\prime}\right)^{2}} .
$$


Proof. Take the derivative of $I\left(c_{N}^{\prime} ; c_{N}\right)$ with respect to $c_{N}$ :

$$
\frac{\partial I\left(c_{N}^{\prime} ; c_{N}\right)}{\partial c_{N}}=\frac{\sqrt{c_{N}}\left(\sqrt{c_{N}^{\prime}}-\left(c_{I}+c_{N}^{\prime}\right) \sqrt{x_{I}^{A I}\left(\tilde{c}_{N}\right)}\right)}{c_{N}^{2}\left(c_{I}+c_{N}^{\prime}\right)}
$$

This is negative if and only if

$$
\sqrt{c_{N}^{\prime}}-\left(c_{I}+c_{N}^{\prime}\right) \sqrt{x_{I}^{A I}\left(\tilde{c}_{N}\right)}<0 \Leftrightarrow x_{I}^{A I}\left(\tilde{c}_{N}\right)>\frac{c_{N}^{\prime}}{\left(c_{I}+c_{N}^{\prime}\right)^{2}} .
$$

Because $x_{I}^{A I}\left(\tilde{c}_{N}\right)=\frac{\tilde{c}_{N}}{\left(c_{I}+\tilde{c}_{N}\right)^{2}}$ and $c_{N}^{\prime}<\tilde{c}_{N}$, this is always the case.

If $\tilde{c}_{N}$ has no incentive to mimic a given $c_{N}^{\prime}<\tilde{c}_{N}$, neither has another type with $c_{N}>\tilde{c}_{N}$. Thus, we established existence of a MIE with threshold newbie type $\tilde{c}_{N}$.

Next consider comparative statics. Condition (4) determines the MIE threshold. Using the implicit function theorem, we know that $\left.\frac{d c_{Z}}{d c_{I}}\right|_{c_{Z}=\tilde{c}_{N}}=-\left.\frac{\frac{\partial \Delta x_{I}}{\partial c_{I}}}{\frac{\partial \Delta x_{I}}{\partial c_{Z}}}\right|_{c_{Z}=\tilde{c}_{N}}$ or

$$
\left.\frac{d c_{Z}}{d c_{I}}\right|_{c_{Z}=\tilde{c}_{N}}=-\frac{\frac{2\left(1-F\left(\tilde{c}_{N}\right)\right)\left(\int_{\tilde{c}_{N}}^{c_{H}} \sqrt{c} d F(c)\right)^{2}}{\left(c_{I}\left(1-F\left(\tilde{c}_{N}\right)\right)+\int_{\tilde{c}_{N}}^{c_{H}} c d F(c)\right)^{3}}-\frac{2 \tilde{c}_{N}}{\left(c_{I}+\tilde{c}_{N}\right)^{3}}}{\frac{2 f\left(\tilde{c}_{N}\right)\left(\int_{\tilde{c}_{N}}^{c_{H}} \sqrt{c} d F(c)\right)\left(c_{I} \sqrt{\tilde{c}_{N}}\left(1-F\left(\tilde{c}_{N}\right)\right)-\left(c_{I}+\tilde{c}_{N}\right) \int_{\tilde{c}_{N}}^{c_{H}} \sqrt{c} d F(c)+\sqrt{\tilde{c}_{N}} \int_{\tilde{c}_{N}}^{c_{1}} c d F(c)\right)}{\left(c_{I}\left(1-F\left(\tilde{c}_{N}\right)\right)+\int_{\tilde{c}_{N}}^{c_{H}} c d F(c)\right)^{3}}+\frac{c_{I}-\tilde{c}_{N}}{\left(c_{I}+\tilde{c}_{N}\right)^{3}}}
$$

First note that the denominator is strictly positive since $c_{I}>\tilde{c}_{N}$ and $c_{I} \sqrt{\tilde{c}_{N}}\left(1-F\left(\tilde{c}_{N}\right)\right)-\left(c_{I}+\right.$ $\left.\tilde{c}_{N}\right) \int_{\tilde{c}_{N}}^{c_{H}} \sqrt{c} d F(c)+\sqrt{\tilde{c}_{N}} \int_{\tilde{c}_{N}}^{c_{H}} c d F(c)=0$. Thus, the sign of the derivative turns on the numerator's sign. The numerator is positive if and only if

$$
\begin{aligned}
& \frac{2\left(1-F\left(\tilde{c}_{N}\right)\right)\left(\int_{\tilde{c}_{N}}^{c_{H}} \sqrt{c} d F(c)\right)^{2}}{\left(c_{I}\left(1-F\left(\tilde{c}_{N}\right)\right)+\int_{\tilde{c}_{N}}^{c} c d F(c)\right)^{3}}-\frac{2 \tilde{c}_{N}}{\left(c_{I}+\tilde{c}_{N}\right)^{3}}>0 \Leftrightarrow \frac{\left(1-F\left(\tilde{c}_{N}\right)\right)\left(\int_{\tilde{c}_{N}}^{c_{H}} \sqrt{c} d F(c)\right)^{2}}{\left(c_{I}\left(1-F\left(\tilde{c}_{N}\right)\right)+\int_{\tilde{c}_{N}}^{c} c d F(c)\right)^{3}}-\frac{\tilde{c}_{N}}{\left(c_{I}+\tilde{c}_{N}\right)^{3}}>0 \\
& \Leftrightarrow \frac{\left(1-F\left(\tilde{c}_{N}\right)\right)}{\left(c_{I}\left(1-F\left(\tilde{c}_{N}\right)\right)+\int_{\tilde{c}_{N}}^{c_{H}} c d F(c)\right)} x_{I}^{A I}-x_{I}^{C I} \frac{1}{c_{I}+\tilde{c}_{N}}>0 \Leftrightarrow \frac{\left(1-F\left(\tilde{c}_{N}\right)\right)}{\left(c_{I}\left(1-F\left(\tilde{c}_{N}\right)\right)+\int_{\tilde{c}_{N}}^{c_{H}} c d F(c)\right)}>\frac{1}{c_{I}+\tilde{c}_{N}} \\
& \Leftrightarrow \frac{1}{\left(c_{I}+\frac{\int_{\tilde{c}_{N}}^{c_{N}} c d F(c)}{\left(1-F\left(\tilde{c}_{N}\right)\right)}\right)}>\frac{1}{c_{I}+\tilde{c}_{N}} \Leftrightarrow \frac{\int_{\tilde{c}_{N}}^{c_{H}} c d F(c)}{\left(1-F\left(\tilde{c}_{N}\right)\right)}<\tilde{c}_{N}
\end{aligned}
$$

But this is impossible. Thus, the numerator must be negative and therefore the derivative is positive: $\tilde{c}_{N}$ increases in $c_{I}$.

For low enough $c_{I}$, the threshold is lower than $c_{L}$ and thus no showing off takes place. Denote the first $c_{I}$ such that no showing off takes place by $\tilde{c}_{I}$. This $\tilde{c}_{I}$ solves

$$
\frac{c_{L}}{\left(c_{L}+\tilde{c}_{I}\right)^{2}}=\frac{\left(E\left[\sqrt{c_{L}}\right]\right)^{2}}{\left(\tilde{c}_{I}+E\left[c_{L}\right]\right)^{2}} \Leftrightarrow \tilde{c}_{I}=\frac{\sqrt{c_{L}} E\left[c_{L}\right]-c_{L} E\left[\sqrt{c_{L}}\right]}{E\left[\sqrt{c_{L}}\right]-\sqrt{c_{L}}}>0 .
$$

$\tilde{c}_{I}$ is the generalization of $\mu_{N}$ from the binary case. Hence, if $c_{I}>\tilde{c}_{I}$, the most able newbie types show off, while otherwise all newbie types lay low and no information is transmitted. 


\section{Proof of Proposition 2: The Incumbent's Perspective-Binary Case}

Using equilibrium utilities given in Appendix A, the difference in the incumbent's expected utility between complete and asymmetric information is equal to

$$
\begin{aligned}
\Delta \pi_{I}=\pi_{I}^{C I}-\pi_{I}^{A I} & =\frac{q(1-q)\left(\sqrt{c_{H}}-\sqrt{c_{L}}\right)\left(c_{I}-\sqrt{c_{H} c_{L}}\right)}{\left(c_{I}+c_{H}\right)^{2}\left(c_{I}+c_{L}\right)^{2}\left(c_{I}+(1-q) c_{H}+q c_{L}\right)^{2}} \\
& \times\left[c_{I}^{3}\left(2 \sqrt{c_{H} c_{L}}+c_{L}+c_{H}\right)\right. \\
& +c_{I}^{2}\left(\left(c_{H}+c_{L}+(1-q) c_{H}+q c_{L}\right) \sqrt{c_{H} c_{L}}+4 c_{H} c_{L}\right) \\
& \left.+\left(c_{I}^{3}+2 q c_{I}^{2}+c_{H} c_{L}\left(3 c_{I}-\sqrt{c_{H} c_{L}}\right)\right)\left((1-q) c_{H}+q c_{L}\right)\right]
\end{aligned}
$$

If $c_{I}=\sqrt{c_{H} c_{L}}, \Delta \pi_{I}=0$ and the incumbent is indifferent between the newbie showing off or laying low. For $c_{I}>\sqrt{c_{H} c_{L}}$, she prefers to receive information about the newbie's type. Finally, for $c_{I}$ smaller than $\sqrt{c_{H} c_{L}}$, the sign of the difference also depends on $3 c_{I}-\sqrt{c_{H} c_{L}}$, which is decreasing in $c_{H}$ and thus smallest for the highest possible $c_{H}$. Using $c_{H}=2 c_{L}$, which is the largest admissible value of $c_{H}$, it becomes $3 c_{I}-\sqrt{2} c_{L}>0$ by Assumption 1, Thus, for $c_{I}<\sqrt{c_{H} c_{L}}, \Delta \pi_{I}<0$ and the incumbent is better off when the newbie lays low.

\section{Proof of Proposition 3; The Incumbent's Perspective-General Case}

Recall that by Lemma 1

$$
E \pi_{I}=\int_{c_{L}}^{c_{Z}} \frac{c_{N}^{2}}{\left(c_{N}+c_{I}\right)^{2}} d F\left(c_{N}\right)+\frac{\left(\int_{c_{Z}}^{c_{H}} \sqrt{c_{N}} d F\left(c_{N}\right)\right)^{2} \int_{c_{Z}}^{c_{H}} c_{N} d F\left(c_{N}\right)}{\left(c_{I}\left(1-F\left(c_{Z}\right)\right)+\int_{c_{Z}}^{c_{H}} c_{N} d F\left(c_{N}\right)\right)^{2}}
$$

Differentiating with respect to threshold $c_{Z}$ yields

$$
\frac{\partial E \pi_{I}}{\partial c_{Z}}=f\left(c_{Z}\right)\left(\frac{c_{Z}^{2}}{\left(c_{I}+c_{Z}\right)^{2}}-\frac{2 \sqrt{c_{Z}} \gamma_{2}\left(c_{Z}\right) \gamma_{1}\left(c_{Z}\right)}{\left(c_{I}+\gamma_{1}\left(c_{Z}\right)\right)^{2}}+\frac{\gamma_{2}\left(c_{Z}\right)^{2}\left[\left(2 c_{I}+c_{Z}\right) \gamma_{1}\left(c_{Z}\right)-c_{I} c_{Z}\right]}{\left(c_{I}+\gamma_{1}\left(c_{Z}\right)\right)^{3}}\right),
$$

where $\gamma_{1}\left(c_{Z}\right) \equiv \frac{\int_{c_{Z}}^{c_{H}} c_{N} d F\left(c_{N}\right)}{1-F\left(c_{Z}\right)}$ and $\gamma_{2}\left(c_{Z}\right) \equiv \frac{\int_{c_{Z}}^{c_{H}} \sqrt{c_{N}} d F\left(c_{N}\right)}{1-F\left(c_{Z}\right)}$. For the rest of the proof we omit the argument of $\gamma_{1}$ and $\gamma_{2}, c_{Z}$, for better readability of the equations whenever possible. Using $x_{I}^{C I}\left(c_{I}, c_{Z}\right)=\frac{c_{Z}}{\left(c_{I}+c_{Z}\right)^{2}}$ and $x_{I}^{A I}\left(c_{I}, c_{Z}\right)=\frac{\left(\gamma_{2}\right)^{2}}{\left(c_{I}+\gamma_{1}\right)^{2}}$, we can write the FOC for an extremum as

$$
\begin{aligned}
\frac{\partial E \pi_{I}}{\partial c_{Z}}= & f\left(c_{Z}\right)\left(c_{Z} x_{I}^{C I}\left(c_{I}, c_{Z}\right)-\frac{2 \sqrt{c_{Z}} \gamma_{1}}{\gamma_{2}} x_{I}^{A I}\left(c_{I}, c_{Z}\right)+\frac{\left(\left(2 c_{I}+c_{Z}\right) \gamma_{1}-c_{I} c_{Z}\right)}{\left(c_{I}+\gamma_{1}\right)} x_{I}^{A I}\left(c_{I}, c_{Z}\right)\right) \\
= & f\left(c_{Z}\right) c_{Z}\left(\sqrt{x_{I}^{C I}\left(c_{I}, c_{Z}\right)}-\sqrt{x_{I}^{A I}\left(c_{I}, c_{Z}\right)}\right) \\
& \left(\sqrt{x_{I}^{C I}\left(c_{I}, c_{Z}\right)}+\sqrt{x_{I}^{A I}\left(c_{I}, c_{Z}\right)}-\frac{2 \gamma_{1}}{\gamma_{2} \sqrt{c_{Z}}} \frac{x_{I}^{A I}\left(c_{I}, c_{Z}\right)}{\sqrt{x_{I}^{C I}\left(c_{I}, c_{Z}\right)}}\right)=0 .
\end{aligned}
$$


and thus we have a local extremum when $x_{I}^{C I}\left(c_{I}, c_{Z}\right)=x_{I}^{A I}\left(c_{I}, c_{Z}\right)$. By Lemma 4 this happens only at the MIE and when $c_{Z}=c_{H}$. Next we show that this is the only possible type of extremum in the relevant range, i.e., we show that

$$
\begin{aligned}
\zeta\left(c_{Z}\right) & \equiv f\left(c_{Z}\right) c_{Z}\left(\sqrt{x_{I}^{C I}\left(c_{I}, c_{Z}\right)}+\sqrt{x_{I}^{A I}\left(c_{I}, c_{Z}\right)}-\frac{2 \gamma_{1}}{\gamma_{2} \sqrt{c_{Z}}} \frac{x_{I}^{A I}\left(c_{I}, c_{Z}\right)}{\sqrt{x_{I}^{C I}\left(c_{I}, c_{Z}\right)}}\right)<0 \\
& \Leftrightarrow \sqrt{x_{I}^{C I}\left(c_{I}, c_{Z}\right)}+\sqrt{x_{I}^{A I}\left(c_{I}, c_{Z}\right)}-\frac{2 \gamma_{1}}{\gamma_{2} \sqrt{c_{Z}}} \frac{x_{I}^{A I}\left(c_{I}, c_{Z}\right)}{\sqrt{x_{I}^{C I}\left(c_{I}, c_{Z}\right)}}<0
\end{aligned}
$$

for $c_{L} \leq c_{Z}<c_{H}$. First note that this expression is negative when $x_{I}^{C I}\left(c_{I}, c_{Z}\right)=x_{I}^{A I}\left(c_{I}, c_{Z}\right)$ because

$$
\frac{2 \gamma_{1}}{\gamma_{2} \sqrt{c_{Z}}}>2
$$

as $\gamma_{2}>\sqrt{c_{Z}}$ and $\gamma_{1}>\left(\gamma_{2}\right)^{2}$ by Jensen's inequality. More generally the expression is always negative when $x_{I}^{C I} \leq x_{I}^{A I}$ which is true for any $c_{Z}<\tilde{c}_{Z}$ by Lemma 4 . Thus the MIE constitutes the only extremum on $c_{Z} \in\left[c_{L}, \tilde{c}_{Z}\right]$. To prove that it is also negative for all $c_{Z} \geq \tilde{c}_{Z}$ we will construct bounds on the inequality in (D). First we multiply by $\sqrt{x_{I}^{C I}\left(c_{I}, c_{Z}\right)}$ and insert back the expressions for $x_{I}^{A I}\left(c_{I}, c_{Z}\right)$ and $x_{I}^{C I}\left(c_{I}, c_{Z}\right)$ to get

$$
\frac{c_{Z}}{\left(c_{I}+c_{Z}\right)^{2}}+\frac{\gamma_{2}}{c_{I}+\gamma_{1}} \frac{\sqrt{c_{Z}}}{c_{I}+c_{Z}}-\frac{2 \gamma_{1}}{\sqrt{c_{Z}}} \frac{\gamma_{2}}{\left(c_{I}+\gamma_{1}\right)^{2}}<0
$$

Now we multiply by $\left(c_{I}+\gamma_{1}\right)^{2}$ to get

$$
\frac{\left(c_{I}+\gamma_{1}\right)^{2}}{\left(c_{I}+c_{Z}\right)^{2}} c_{Z}+\frac{\left(c_{I}+\gamma_{1}\right)}{c_{I}+c_{Z}} \gamma_{2} \sqrt{c_{Z}}-\frac{2 \gamma_{1}}{\sqrt{c_{Z}}} \gamma_{2}<0
$$

Note that $\frac{\left(c_{I}+\gamma_{1}\right)}{\left(c_{I}+c_{Z}\right)}$ is decreasing in $c_{I}$ and thus, in order to bound the LHS of the inequality (and show that it cannot be positive), we can insert the lower bound $c_{I}=c_{L}$ in this expression. This lower bound is smallest for a given $c_{H}$ when $c_{L}$ is the smallest possible (according to Assumption 1) and thus we use $c_{I}=c_{L}=c_{H} / 2$ :

$$
\frac{\left(\frac{c_{H}}{2}+\gamma_{1}\right)^{2}}{\left(\frac{c_{H}}{2}+c_{Z}\right)^{2}} c_{Z}+\frac{\left(\frac{c_{H}}{2}+\gamma_{1}\right)}{\frac{c_{H}}{2}+c_{Z}} \gamma_{2} \sqrt{c_{Z}}-\frac{2 \gamma_{1}}{\sqrt{c_{Z}}} \gamma_{2}<0 .
$$

Furthermore, we can bound $c_{H}$ in $\frac{\left(\frac{c_{H}}{2}+\gamma_{1}\right)}{\frac{c_{H}}{2}+c_{Z}}$ by $\gamma_{1}$ as $c_{H} \geq \gamma_{1}$ and thus our inequality, after simplifying and dividing by $\gamma_{1}$, becomes

$$
\frac{\gamma_{1}\left(\frac{3}{2}\right)^{2}}{\left(\frac{\gamma_{1}}{2}+c_{Z}\right)^{2}} c_{Z}+\frac{\left(\frac{3}{2}\right)}{\frac{\gamma_{1}}{2}+c_{Z}} \gamma_{2} \sqrt{c_{Z}}-\frac{2}{\sqrt{c_{Z}}} \gamma_{2}<0 .
$$


Next note that the last two terms are linear and decreasing in $\gamma_{2}$ and thus we can bound the inequality further by setting $\gamma_{2}=\sqrt{c_{Z}}$, its lower bound, to get

$$
\frac{\gamma_{1}\left(\frac{3}{2}\right)^{2}}{\left(\frac{\gamma_{1}}{2}+c_{Z}\right)^{2}} c_{Z}+\frac{\left(\frac{3}{2}\right)}{\frac{\gamma_{1}}{2}+c_{Z}} c_{Z}-2<0
$$

Finally, the first two terms are decreasing in $\gamma_{1}$ and thus we can bound the inequality by setting $\gamma_{1}=c_{Z}$, its lower bound, to get

$$
\frac{c_{Z}\left(\frac{3}{2}\right)^{2}}{\left(\frac{3}{2} c_{Z}\right)^{2}} c_{Z}+\frac{\left(\frac{3}{2}\right)}{\frac{3}{2} c_{Z}} c_{Z}-2=0
$$

Thus, except in the limit case, in which $c_{Z}=c_{H}$, the inequality in (D) is strict. As a consequence, all extrema of the incumbent's expected utility function must fulfill $x_{I}^{C I}=x_{I}^{A I}$. From Lemma 4 we know that this happens no more than twice: at the MIE and at $c_{Z}=c_{H}$.

In order to check the SOC we need to check the second derivative of the incumbent's expected utility with respect to $c_{Z}$ at the MIE. This reveals that

$$
\begin{aligned}
\left.\frac{\partial^{2} E \pi_{I}}{\partial c_{Z}^{2}}\right|_{c_{Z}=\tilde{c}_{Z}} & =\zeta^{\prime}\left(c_{Z}\right)\left(\left.\sqrt{x_{I}^{C I}}\right|_{c_{Z}=\tilde{c}_{Z}}-\left.\sqrt{x_{I}^{A I}}\right|_{c_{Z}=\tilde{c}_{Z}}\right)+\zeta\left(c_{Z}\right)\left(\left.\frac{\partial \sqrt{x_{I}^{C I}}}{\partial c_{Z}}\right|_{c_{Z}=\tilde{c}_{Z}}-\left.\frac{\partial \sqrt{x_{I}^{A I}}}{\partial c_{Z}}\right|_{c_{Z}=\tilde{c}_{Z}}\right) \\
& =\left.\zeta\left(c_{Z}\right) \frac{\partial \sqrt{x_{I}^{C I}}}{\partial c_{Z}}\right|_{c_{Z}=\tilde{c}_{Z}}
\end{aligned}
$$

Because $\frac{\partial \sqrt{x_{I}^{C I}\left(c_{I}, c_{Z}\right)}}{\partial c_{Z}}=\frac{1}{2 \sqrt{x_{I}^{C I}\left(c_{I}, c_{Z}\right)}} \frac{\partial x_{I}^{C I}\left(c_{I}, c_{Z}\right)}{\partial c_{Z}}>0$ and $\frac{\partial \sqrt{x_{I}^{A I}\left(c_{I}, c_{Z}\right)}}{\partial c_{Z}}=\frac{1}{2 \sqrt{x_{I}^{A I}\left(c_{I}, c_{Z}\right)}} \frac{\partial x_{I}^{A I}\left(c_{I}, c_{Z}\right)}{\partial c_{Z}}=0$ at the MIE (see Lemma 4) and $\zeta\left(c_{Z}\right)<0,\left.\frac{\partial^{2} E \pi_{I}}{\partial c_{Z}^{2}}\right|_{c_{Z}=\tilde{c}_{Z}}<0$ and thus the MIE constitutes a global expected utility maximum for the incumbent. Note that we have shown that the MIE is a local maximum also when $4 c_{L} \geq c_{H}>c_{L}$, which is more permissive than Assumption 11 However, in this case we cannot exclude that the incumbent prefers another threshold type $c_{Z}>\tilde{c}_{Z}$ over the MIE.

\section{E Proof of Theorem 2: Norm Against Showing Off}

Recall that because of Lemma 1, expected aggregate effort given threshold type $c_{Z}$ is

$$
E X=\int_{c_{L}}^{c_{Z}} \frac{1}{c_{N}+c_{I}} d F\left(c_{N}\right)+\frac{\int_{c_{Z}}^{c_{H}} \sqrt{c_{N}} d F\left(c_{N}\right) \int_{c_{Z}}^{c_{H}} \frac{1}{\sqrt{c_{N}}} d F\left(c_{N}\right)}{\left(c_{I}\left(1-F\left(c_{Z}\right)\right)+\int_{c_{Z}}^{c_{H}} c_{N} d F\left(c_{N}\right)\right)}
$$

Taking the derivative with respect to $c_{Z}$ yields

$$
\frac{\partial E X}{\partial c_{Z}}=f\left(c_{Z}\right)\left(\frac{\left(c_{I}+c_{Z}\right) \gamma_{2}\left(c_{Z}\right) \gamma_{3}\left(c_{Z}\right)}{\left(\gamma_{1}\left(c_{Z}\right)+c_{I}\right)^{2}}-\frac{\sqrt{c_{Z}} \gamma_{3}\left(c_{Z}\right)}{\left(\gamma_{1}\left(c_{Z}\right)+c_{I}\right)}-\frac{\gamma_{2}\left(c_{Z}\right)}{\sqrt{c_{Z}}\left(\gamma_{1}\left(c_{Z}\right)+c_{I}\right)}+\frac{1}{c_{I}+c_{Z}}\right)
$$


where $\gamma_{3}\left(c_{Z}\right) \equiv \frac{\int_{c_{Z}}^{c_{H}} \frac{f\left(c_{N}\right)}{\sqrt{c_{N}}} d c_{N}}{1-F\left(c_{Z}\right)}$ and, as before, $\gamma_{1}\left(c_{Z}\right) \equiv \frac{\int_{c_{Z}}^{c_{H}} c_{N} d F\left(c_{N}\right)}{1-F\left(c_{Z}\right)}$ and $\gamma_{2}\left(c_{Z}\right) \equiv \frac{\int_{c_{Z}}^{c_{H}} \sqrt{c_{N}} d F\left(c_{N}\right)}{1-F\left(c_{Z}\right)}$. As before, for better readability we suppress the argument of $\gamma_{1}, \gamma_{2}$ and $\gamma_{3}$ whenever possible. Rewriting this derivative in terms of incumbent effort against the threshold newbie $x_{I}^{C I}\left(c_{I}, c_{Z}\right)$ and incumbent effort under asymmetric information given threshold $c_{Z}, x_{I}^{A I}\left(c_{I}, c_{Z}\right)$, we get

$$
\frac{\partial E X}{\partial c_{Z}}=f\left(c_{Z}\right)\left(\sqrt{x_{I}^{C I}\left(c_{I}, c_{Z}\right)}-\sqrt{x_{I}^{A I}\left(c_{I}, c_{Z}\right)}\right)\left(\frac{1}{\sqrt{c_{Z}}}-\frac{\left(c_{I}+c_{Z}\right) \gamma_{3}}{\left(\gamma_{1}+c_{I}\right)}\right)
$$

and thus we again have a local extremum when $x_{I}^{C I}\left(c_{I}, c_{Z}\right)=x_{I}^{A I}\left(c_{I}, c_{Z}\right)$. Again, by Lemma 4 this happens only at the MIE and when $c_{Z}=c_{H}$. Next we show that this is the only possible type of extremum in the relevant range, i.e., we show that

$$
\frac{1}{\sqrt{c_{Z}}} \neq \frac{\left(c_{I}+c_{Z}\right) \gamma_{3}}{\left(\gamma_{1}+c_{I}\right)}
$$

Rewriting, the sign of the expression in brackets turns on

$$
\frac{\left(\gamma_{1}+c_{I}\right)}{\left(c_{Z}+c_{I}\right)}-\sqrt{c_{Z}} \gamma_{3}
$$

Note that $\sqrt{c_{Z}} \gamma_{3}=\int_{c_{Z}}^{c_{H}} \frac{\sqrt{c_{Z}}}{\sqrt{c_{N}}} f\left(c_{N}\right) d c_{N} /\left(1-F\left(c_{Z}\right)\right)<1$ when $c_{Z}<c_{H}$. Furthermore, $\gamma_{1}>c_{Z}$. Thus the first term is larger than one and the second one smaller than one and thus it always holds that

$$
\frac{\left(\gamma_{1}+c_{I}\right)}{\left(c_{Z}+c_{I}\right)}-\sqrt{c_{Z}} \gamma_{3}>0
$$

Next take a look at the SOC at the extrema, i.e., when $x_{I}^{C I}\left(c_{I}, c_{Z}\right)=x_{I}^{A I}\left(c_{I}, c_{Z}\right)$. The second derivative of expected aggregate effort with respect to $c_{Z}$ simplifies considerably to

$$
\left.\frac{\partial^{2} E X}{\partial c_{Z}^{2}}\right|_{x_{I}^{C I}=x_{I}^{A I}}=f\left(c_{Z}\right) \frac{\partial\left(\sqrt{x_{I}^{C I}\left(c_{I}, c_{Z}\right)}\right)}{\partial c_{Z}}\left(\frac{1}{\sqrt{c_{Z}}}-\frac{\left(c_{I}+c_{Z}\right) \gamma_{3}}{\left(\gamma_{1}+c_{I}\right)}\right)
$$

where we used $\frac{\partial x_{I}^{A I}\left(c_{Z}\right)}{\partial c_{Z}}=0$ when $x_{I}^{C I}\left(c_{I}, c_{Z}\right)=x_{I}^{A I}\left(c_{I}, c_{Z}\right)$ (see Lemma 4) as well as the FOC. Note that $\frac{\partial \sqrt{x_{I}^{C I}\left(c_{I}, c_{Z}\right)}}{\partial c_{Z}}>0$ at the MIE. Thus $\left.\frac{\partial^{2} E X}{\partial c_{Z}^{2}}\right|_{c_{Z}=\tilde{c}_{N}}>0$ and the MIE constitutes a global expected aggregate effort minimum. 


\section{F Proof of Theorem 3: Showing Off and Selection}

We define expected efficiency as the expected marginal cost of effort of the contest winner given threshold newbie type $c_{Z}$, i.e.:

$$
\begin{aligned}
E E\left(c_{Z}\right) & \equiv E\left[c_{i} \mid i \text { wins }\right] \\
& =\int_{c_{L}}^{c_{H}}\left(\frac{x_{N}\left(c_{Z}, c_{N}\right)}{x_{N}\left(c_{Z}, c_{N}\right)+x_{I}\left(c_{Z}, c_{N}\right)} c_{N}+\frac{x_{I}\left(c_{Z}, c_{N}\right)}{x_{N}\left(c_{Z}, c_{N}\right)+x_{I}\left(c_{Z}, c_{N}\right)} c_{I}\right) d F\left(c_{N}\right) \\
& =\int_{c_{L}}^{c_{H}}\left(\frac{x_{N}\left(c_{Z}, c_{N}\right)}{x_{N}\left(c_{Z}, c_{N}\right)+x_{I}\left(c_{Z}, c_{N}\right)} c_{N}+\left(1-\frac{x_{I}\left(c_{Z}, c_{N}\right)}{x_{N}\left(c_{Z}, c_{N}\right)+x_{I}\left(c_{Z}, c_{N}\right)}\right) c_{I}\right) d F\left(c_{N}\right) \\
& =\int_{c_{L}}^{c_{H}} \frac{x_{N}\left(c_{Z}, c_{N}\right)}{x_{N}\left(c_{Z}, c_{N}\right)+x_{I}\left(c_{Z}, c_{N}\right)}\left(c_{N}-c_{I}\right) d F\left(c_{N}\right)+c_{I} \\
& =\int_{c_{L}}^{c_{Z}}\left(c_{N}-c_{I}\right) \frac{x_{N}^{C I}\left(c_{N}\right)}{x_{N}^{C I}\left(c_{N}\right)+x_{I}^{C I}\left(c_{N}\right)} d F\left(c_{N}\right) \\
& +\int_{c_{Z}}^{c_{H}}\left(c_{N}-c_{I}\right) \frac{x_{N}^{A I}\left(c_{N}\right)}{x_{N}^{A I}\left(c_{N}\right)+x_{I}^{A I}\left(c_{Z}\right)} d F\left(c_{N}\right)+c_{I} \\
& =\int_{c_{L}}^{c_{Z}}\left(c_{N}-c_{I}\right) \frac{c_{I}}{c_{I}+c_{N}} d F\left(c_{N}\right)+\int_{c_{Z}}^{c_{H}}\left(c_{N}-c_{I}\right)\left(1-\sqrt{c_{N}} \frac{\gamma_{2}\left(c_{Z}\right)}{c_{I}+\gamma_{1}\left(c_{Z}\right)}\right) d F\left(c_{N}\right)+c_{I}
\end{aligned}
$$

$\gamma_{1}\left(c_{Z}\right)$ and $\gamma_{2}\left(c_{Z}\right)$ are defined as before. Using

$$
\begin{aligned}
\frac{\partial \frac{\gamma_{2}\left(c_{Z}\right)}{c_{I}+\gamma_{1}\left(c_{Z}\right)}}{\partial c_{Z}} & =-f\left(c_{Z}\right) \frac{\left(c_{I}+\gamma_{1}\left(c_{Z}\right)\right) \sqrt{c_{Z}}-\left(c_{I}+c_{Z}\right) \gamma_{2}\left(c_{Z}\right)}{\left(1-F\left(c_{Z}\right)\right)\left(c_{I}+\gamma_{1}\left(c_{Z}\right)\right)^{2}} \\
& =-\frac{f\left(c_{Z}\right)\left(c_{I}+c_{Z}\right)}{\left(1-F\left(c_{Z}\right)\right)\left(c_{I}+\gamma_{1}\left(c_{Z}\right)\right)}\left(\frac{\sqrt{c_{Z}}}{\left(c_{I}+c_{Z}\right)}-\frac{\gamma_{2}\left(c_{Z}\right)}{\left(c_{I}+\gamma_{1}\left(c_{Z}\right)\right)}\right) \\
& =\frac{f\left(c_{Z}\right)\left(c_{I}+c_{Z}\right)}{\left(1-F\left(c_{Z}\right)\right)\left(c_{I}+\gamma_{1}\left(c_{Z}\right)\right)}\left(\sqrt{x_{I}^{A I}\left(c_{Z}\right)}-\sqrt{x_{I}^{C I}\left(c_{N}\right)}\right)
\end{aligned}
$$

the derivative of $E E\left(c_{Z}\right)$ with respect to $c_{Z}$, can be written as

$$
\begin{aligned}
\frac{\partial E E\left(c_{Z}\right)}{\partial c_{Z}}= & f\left(c_{Z}\right)\left[\left(c_{Z}-c_{I}\right) \frac{c_{I}}{c_{I}+c_{Z}}-\left(c_{Z}-c_{I}\right)\left(1-\sqrt{c_{Z}} \frac{\gamma_{2}}{c_{I}+\gamma_{1}}\right)\right. \\
& \left.-\int_{c_{Z}}^{c_{H}}\left(c_{N}-c_{I}\right) \sqrt{c_{N}} \frac{\frac{\gamma_{2}\left(c_{Z}\right)}{c_{I}+\gamma_{1}\left(c_{Z}\right)}}{\partial c_{Z}} d F\left(c_{N}\right) \frac{1}{f\left(c_{Z}\right)}\right] \\
= & f\left(c_{Z}\right)\left[\left(c_{Z}-c_{I}\right) \sqrt{c_{Z}}\left(\sqrt{x_{I}^{A I}\left(c_{Z}\right)}-\sqrt{x_{I}^{C I}\left(c_{N}\right)}\right)\right. \\
& \left.-\int_{c_{Z}}^{c_{H}}\left(c_{N}-c_{I}\right) \sqrt{c_{N}} \frac{f\left(c_{Z}\right)\left(c_{I}+c_{Z}\right)}{\left(1-F\left(c_{Z}\right)\left(c_{I}+\gamma_{1}\left(c_{Z}\right)\right)\right.}\left(\sqrt{x_{I}^{A I}\left(c_{Z}\right)}-\sqrt{x_{I}^{C I}\left(c_{N}\right)}\right) d F\left(c_{N}\right) \frac{1}{f\left(c_{Z}\right)}\right] \\
= & f\left(c_{Z}\right)\left(\sqrt{x_{I}^{A I}\left(c_{Z}\right)}-\sqrt{x_{I}^{C I}\left(c_{N}\right)}\right) \\
& \times\left(\left(c_{Z}-c_{I}\right) \sqrt{c_{Z}}-\int_{c_{Z}}^{c_{H}}\left(c_{N}-c_{I}\right) \sqrt{c_{N}} \frac{\left(c_{I}+c_{Z}\right)}{\left(1-F\left(c_{Z}\right)\right)\left(c_{I}+\gamma_{1}\left(c_{Z}\right)\right)} d F\left(c_{N}\right)\right) .
\end{aligned}
$$

We know from Lemma 4 that except at the MIE and at $c_{Z}=c_{H}, x_{I}^{A I}\left(c_{Z}\right) \neq x_{I}^{C I}\left(c_{Z}\right)$, and thus the MIE constitutes a local extremum of $E E\left(c_{Z}\right)$. Any other extremum in the relevant region must satisfy

$$
\left(c_{Z}-c_{I}\right) \sqrt{c_{Z}}-\frac{\left(c_{I}+c_{Z}\right)}{\left(c_{I}+\gamma_{1}\left(c_{Z}\right)\right)} \frac{\int_{c_{Z}}^{c_{H}}\left(c_{N}-c_{I}\right) \sqrt{c_{N}} d F\left(c_{N}\right)}{\left(1-F\left(c_{Z}\right)\right)}=0 .
$$


At $c_{Z}=c_{I}<c_{H}$, this cannot be the case, because

$$
-\frac{2 c_{I}}{\left(c_{I}+\gamma_{1}\left(c_{I}\right)\right)} \frac{\int_{c_{I}}^{c_{H}}\left(c_{N}-c_{I}\right) \sqrt{c_{N}} d F\left(c_{N}\right)}{\left(1-F\left(c_{I}\right)\right)}<0 .
$$

If we can show that the LHS of equation (7) is strictly negative for all $c_{Z}<c_{I}$, we prove that the MIE is the only extremum on $\left[c_{L}, c_{I}\right]$.

First note that $\left(c_{Z}-c_{I}\right) \sqrt{c_{Z}}$ is negative and strictly increasing in $c_{Z}$ when $c_{Z}<c_{I} \leq 2 c_{Z}$ which is the relevant range taking into account Assumption 1. Also note that the second term is $\frac{\left(c_{I}+c_{Z}\right)}{\left(c_{I}+\gamma_{1}\left(c_{Z}\right)\right)} E\left[\left(c_{N}-c_{I}\right) \sqrt{c_{N}} \mid c_{N} \geq c_{Z}\right]$, where $\frac{\left(c_{I}+c_{Z}\right)}{\left(c_{I}+\gamma_{1}\left(c_{Z}\right)\right)} \leq 1$ and strictly so for $c_{Z}<c_{H}$. We know already that for $c_{Z}=c_{I}$ the LHS of equation (17) is negative. Now decrease $c_{Z}$ starting at this point. Then the left term turns and remains strictly negative, while the right term might be positive, zero, or negative, depending on $c_{I}$ and $c_{Z}$. As long as the right term is positive or zero, the difference must remain negative, because we subtract a positive term from a negative term. If the second term turns negative as well for some $c_{Z}$, we must compare their magnitudes. Because $\left(c_{Z}-c_{I}\right) \sqrt{c_{Z}}$ is negative and strictly increases in $c_{Z}$ in the relevant range it holds that

$$
0>\frac{\left(c_{I}+c_{Z}\right)}{\left(c_{I}+\gamma_{1}\left(c_{Z}\right)\right)} E\left[\left(c_{N}-c_{I}\right) \sqrt{c_{N}} \mid c_{N} \geq c_{Z}\right]>E\left[\left(c_{N}-c_{I}\right) \sqrt{c_{N}} \mid c_{N} \geq c_{Z}\right]>\sqrt{c_{Z}}\left(c_{Z}-c_{I}\right),
$$

and thus the difference remains strictly negative (as long as $c_{Z}<c_{H}$ ). Consequently, there is no other extremum for $c_{Z}<c_{I}$ apart from the MIE. Using $x_{I}^{A I}\left(c_{Z}\right)=x_{I}^{C I}\left(c_{Z}\right)$ as well as $\frac{\partial x_{I}^{A I}\left(c_{Z}\right)}{\partial c_{Z}}=0$ when $c_{Z}=\tilde{c}_{N}$ (see Lemma 4),

$$
\left.\frac{\partial^{2} E E\left(c_{Z}\right)}{\partial c_{Z}^{2}}\right|_{c_{Z}=\tilde{c}_{N}}=-f\left(c_{Z}\right) \frac{\partial\left(\sqrt{x_{I}^{C I}\left(c_{I}, c_{Z}\right)}\right)}{\partial c_{Z}}\left(\left(c_{Z}-c_{I}\right) \sqrt{c_{Z}}-\frac{\left(c_{I}+c_{Z}\right)}{\left(c_{I}+\gamma_{1}\left(c_{Z}\right)\right)} \frac{\int_{c_{Z}}^{c_{H}}\left(c_{N}-c_{I}\right) \sqrt{c_{N}} d F\left(c_{N}\right)}{\left(1-F\left(c_{Z}\right)\right)}\right) .
$$

We know from our above analysis that $\frac{\partial\left(\sqrt{x_{I}^{C I}\left(c_{I}, c_{Z}\right)}\right)}{\partial c_{Z}}>0$ and the expression in parentheses is negative on $c_{Z} \in\left[c_{L}, c_{I}\right]$ and therefore $\left.\frac{\partial^{2} E E\left(c_{Z}\right)}{\partial c_{Z}^{2}}\right|_{c_{Z}=\tilde{c}_{N}}>0$, proving that the MIE maximizes expected efficiency (minimizes the expected marginal cost of the winner) in that range.

\section{G Proof of Proposition 4: Overconfidence}

To prove the result regarding overconfidence, consider the following modification of the model. As before, the newbie can be of two types. He is talented with probability $q$ or untalented with probability $1-q$. He is always fully aware of his true ability when he is talented, but he may exhibit overconfidence when untalented. In particular, with probability $b \leq 1-q$ he is untalented but wrongly believes to be talented and does not consider the possibility of being overconfident. As such an untalented and overconfident newbie, he will choose an effort level such that he incurs the same effort cost a talented type would incur in equilibrium. The idea behind this is that he sees himself working as hard as the talented type, but the resulting effective effort $x_{i}$ will be only $x_{i} \frac{c_{L}}{c_{H}}<x_{i}$. Thus, while the overconfident newbie thinks he is productive, he is not. We assume 
that ex-ante the incumbent holds biased beliefs as well and thus thinks she is facing a talented newbie with probability $q+b$ and an untalented one with probability $1-q-b$.

The newbie's incentives to show off are unchanged - the Law of Exceptionalism applies. Whether showing off happens turns only on the relation of the incumbent's talent $c_{I}$ to the geometric mean of the newbie's potential types $\mu_{N}=\sqrt{c_{H} c_{L}}$ and not the respective probabilities with which these occur. Thus, a newbie that believes to be strong shows off if and only if $c_{I} \geq \mu_{N}$, which follows from Example 1. In this case, the overconfident newbie types flop and learn through showing off that they are in fact untalented. A truly able newbie, to the contrary, reveals his high talent. The newbie's flopping, or not, will be observed by the incumbent as well. Thus, after showing off, both competitors choose efforts under full information. If $c_{I}<\mu_{N}$, the newbie will not show off in equilibrium and thus no information is revealed. In particular, the incumbent still believes that the newbie is talented with probability $q+b$ while a fraction $b$ of newbie types holds the incorrect belief that they are talented even though they are in fact not.

We now prove Proposition 4 for $b=1-q$. By continuity our results are also valid in a neighborhood of $b=1-q$ for $b$ sufficiently large. Under showing off full information prevails and we can use our previous results to derive equilibrium efforts. Expected aggregate effort equals

$$
E X^{C I}=\frac{c_{I}+q c_{H}+(1-q) c_{L}}{\left(c_{I}+c_{H}\right)\left(c_{I}+c_{L}\right)} \text {. }
$$

When no showing off takes place, the incumbent wrongly believes the likelihood of a talented opponent is $q+b$ and thus maximizes

$$
\max _{x_{I}}(q+b) \frac{x_{I}}{x_{I}+x_{L}}+(1-q-b) \frac{x_{I}}{x_{I}+x_{H}}-c_{I} x_{I}
$$

An untalented, non-overconfident newbie chooses effort

$$
\max _{x_{H}} \frac{x_{H}}{x_{I}+x_{H}}-c_{H} x_{H}
$$

a talented one

$$
\max _{x_{L}} \frac{x_{L}}{x_{I}+x_{L}}-c_{L} x_{L},
$$

while an untalented, overconfident newbie chooses

$$
x_{H L}=\frac{c_{L}}{c_{H}} x_{L} .
$$

This yields the following equilibrium efforts:

$$
x_{I}^{A I}=\frac{c_{L}}{\left(c_{I}+c_{L}\right)^{2}}, \quad x_{L}^{A I}=\frac{c_{I}}{\left(c_{I}+c_{L}\right)^{2}}, \quad x_{H L}^{A I}=\frac{c_{L}}{c_{H}} \frac{c_{I}}{\left(c_{I}+c_{L}\right)^{2}} .
$$


Expected aggregate effort in this case is

$$
E X^{A I}=\frac{\left(c_{I}+c_{H}\right) c_{L}+q c_{I}\left(c_{H}+c_{L}\right)}{c_{H}\left(c_{I}+c_{L}\right)^{2}}
$$

Thus the difference in aggregate effort, after simplifying, is

$$
\Delta E X=\frac{\left(c_{H}-c_{L}\right)\left(c_{I}^{2}-c_{H} c_{L}\right)(1-q)}{c_{H}\left(c_{I}+c_{H}\right)\left(c_{I}+c_{L}\right)^{2}}
$$

which turns only on the sign of $c_{I}^{2}-c_{H} c_{L}$. In particular, aggregate effort is higher for $c_{I}>\sqrt{c_{H} c_{L}}$ under complete information and vice versa if no information is transmitted, which is in contrast to the case with $b=0$. By continuity there exists at least one switching point for each $c_{I}$ such that going from $b=0$ to $b=1-q$ reverses the inequality.

When the incumbent does not learn the newbie's type through showing off, she overestimates the likelihood of facing a strong newbie. This tends to dampen her effort if the newbie is exceptional and increases her effort if the newbie is non-exceptional. For a large enough share of overconfident newbies, the incumbent's effort is thus higher under showing off if and only if the newbie is exceptional. Moreover, the overconfident newbie chooses a different effort level than if he was aware of his true strength. His effort level will be higher than when he knows he is untalented if and only if the incumbent is quite talented $\left(c_{I}<\mu_{N}\right)$. Thus only in this case will the newbie be more aggressive if his bias is not revealed which is exactly what happens in equilibrium. The reason is that in this case a talented newbie competes more fiercely with the incumbent than an untalented one (as they are more similar), and thus the overconfident newbie expends more than if he knew he was untalented. Thus, in the case when there is no showing off and thus no learning of types, i.e., $c_{I}<\mu_{N}$, the biased newbie overinvests in effort to the benefit of the principal. So far we have assumed that also the incumbent holds biased beliefs. This is not necessary for Proposition 4 to hold, though. The same effects can be generated when the incumbent correctly anticipates the newbie's behavior and best-responds to it. In this case, the newbie chooses the efforts characterized above, unaware of his bias. The incumbent on the other hand, best-responds to the newbie's choices. Equilibrium expressions of efforts are available, but the expressions are extremely unwieldy. Thus we show that our results are robust to this setting by example. In particular, consider the case where $c_{L}=1, c_{H}=2$ and $q=0.5$. Figure 5 shows the difference between aggregate effort under complete information and absent information transmission for $b=0, b=\frac{1}{10}$, and $b=\frac{3}{10}$ as a function of $c_{I}$. For $b=\frac{1}{10}$ the results are qualitatively unchanged, while for $b=0.3$ results are exactly reversed.

\section{H Proof of Proposition 5: Productive Signal}

To prove the result we proceed in two steps. First, we derive a bound on the effectiveness $\kappa$ of the productive signal that guarantees that no newbie type finds it profitable to use the productive signal to commit effort greater than the contest efforts in the equilibrium we have studied so far. 


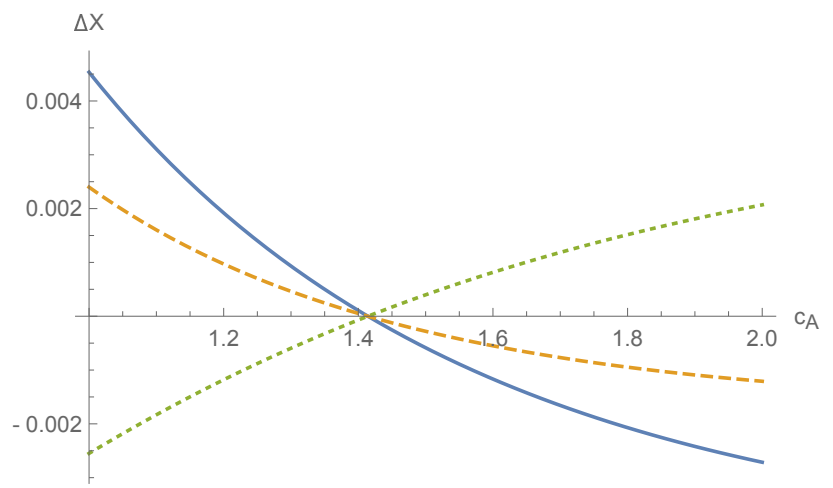

Figure 5: The blue lines shows the difference in expected aggregate effort between full information and asymmetric information for the case where no newbie is overconfident $(b=0)$. The orange (dashed) line shows this difference for a small fraction of overconfident newbies $\left(b=\frac{1}{10}\right)$ while the green (dotted) line shows this difference for the case of a large fraction of overconfident newbies $\left(b=\frac{3}{10}\right)$. As before, when $c_{I}=\sqrt{c_{L} c_{H}}=\mu_{N}=\sqrt{2}$ the differences are zero.

We then prove that incentive compatibility still works and showing off works exactly as it did in the Baseline model.

Commitment. Assume that signaling effort $s_{i}$ translates into contest effort at rate $s_{i} \kappa$. Thus, the newbie's total contest effort equals $s_{N} \kappa+x_{N}$. When $\kappa>0$, the newbie can effectively precommit to effort because he can move first. Note that among all efforts some type of newbie could pre-commit to, the best is the effort he would choose as a Stackelberg leader (see Yildirim, 2005). This effort is $x_{N}^{S B}=\frac{c_{I}}{4 c_{N}^{2}}$. While generally pre-commitment of effort might lead to corner solutions, in which the player who moves second stays passive, Assumption 1 assures an interior equilibrium.

It is well known since Dixit (1987) that in a game like the one we are studying, a player benefits from commiting to an effort level that is greater than the level of effort he would choose in a standard Nash equilibrium, if the player is "stronger" than his opponent. Otherwise, he would like to commit to lower effort. The fact that the newbie chooses effort also in the contest itself prevents him from under-commiting effort, because he would just add as much effort as needed to achieve his Nash equilibrium effort in the normal contest stage (see Lemma 2 of Yildirim, 2005). However, the newbie might overcommit effort, which would change the contest equilibrium. Therefore we need to find a condition under which this is not in the newbie's interest.

As we have established earlier, the newbie's Nash equilibrium effort is $x_{N}^{C I}=\frac{c_{I}}{\left(c_{I}+c_{N}\right)^{2}}$. If he overcommits relative to this effort using the signal $s^{\prime}, \kappa s^{\prime} \geq \frac{c_{I}}{\left(c_{I}+c_{N}\right)^{2}}$, in the contest itself he would choose zero effort, while the incumbent simply best responds (see again Lemma 2 in Yildirim, 2005). In this case, his utility from choosing the signal would be

$$
\pi_{N}^{s}=\frac{\kappa s^{\prime}}{\kappa s^{\prime}+\sqrt{\frac{\kappa s^{\prime}}{c_{I}}}-\kappa s^{\prime}}-c_{N} s^{\prime}=\sqrt{c_{I} \kappa s^{\prime}}-c_{N} s^{\prime} .
$$


Taking the first derivative with respect to $s^{\prime}$ yields

$$
\frac{\partial \pi_{N}^{s}}{\partial s^{\prime}}=\frac{1}{2}\left(c_{I} \kappa s^{\prime}\right)^{-1 / 2}\left(c_{I} \kappa\right)-c_{N} .
$$

Evaluating this at $s^{\prime}=\frac{1}{\kappa} x_{N}^{C I}=\frac{1}{\kappa} \frac{c_{I}}{\left(c_{I}+c_{N}\right)^{2}}$ this derivative must not be positive. Thus we need

$$
\frac{1}{2}\left(c_{I} \kappa \frac{1}{\kappa} \frac{c_{I}}{\left(c_{I}+c_{N}\right)^{2}}\right)^{-1 / 2}\left(c_{I} \kappa\right)-c_{N} \leq 0 \Leftrightarrow \kappa \leq \frac{2 c_{N}}{c_{I}}\left(\frac{c_{I}^{2}}{\left(c_{I}+c_{N}\right)^{2}}\right)^{1 / 2}=\frac{2 c_{N}}{\left(c_{I}+c_{N}\right)} .
$$

Without loss of generality let $c_{I}=\lambda c_{N}, \lambda \in\left(\frac{1}{2}, 2\right)$ (by Assumption 1). Then

$$
\kappa \leq \frac{2 c_{N}}{\left(c_{I}+c_{N}\right)}=\frac{2 c_{N}}{\left(\lambda c_{N}+c_{N}\right)}=\frac{2}{(\lambda+1)}
$$

Since this has to hold for all $\lambda \in\left(\frac{1}{2}, 2\right)$, a sufficient condition is $\kappa \leq \bar{\kappa}=\frac{2}{3}$. Thus when $\kappa \leq \bar{\kappa}=\frac{2}{3}$, the newbie never finds it profitable to precommit to an effort level that is higher than his complete information Nash equilibrium effort and the subsequent contest stage remains unchanged relative to the Baseline model.

Incentive Compatibility. Now let us study the signaling game. Assume the newbie chooses signal $s^{\prime}$. From Lemma 2 in Yildirim (2005) it follows that, if the newbie doesn't overcommit effort and information is revealed truthfully, then the newbie simply adds effort to reach the Nash equilibrium level, $x_{N}^{\prime}=x_{N}^{C I}-\kappa s^{\prime}$. Likewise, the incumbent chooses Nash equilibrium efforts. Thus, along the equilibrium path, the newbie chooses efforts

$$
x_{L}^{\prime}\left(s_{L}\right)=\frac{c_{I}}{\left(c_{I}+c_{L}\right)^{2}}-\kappa s_{L} \text { and } x_{H}^{\prime}\left(s_{H}\right)=\frac{c_{I}}{\left(c_{I}+c_{H}\right)^{2}}-\kappa s_{H},
$$

the incumbent chooses Nash equilibrium efforts, and thus utilities for the newbie types, from the perspective of the signaling stage, are

$$
\begin{aligned}
& \tilde{\pi}_{L}^{C I}=\frac{\kappa s_{L}+x_{L}^{\prime}\left(s_{L}\right)}{\kappa s_{L}+x_{L}^{\prime}\left(s_{L}\right)+x_{I}^{C I}\left(c_{I}, c_{L}\right)}-c_{L} x_{L}^{\prime}\left(s_{L}\right)-c_{L} s_{L}=\frac{c_{I}^{2}}{\left(c_{I}+c_{L}\right)^{2}}-c_{L} s_{L}(1-\kappa), \\
& \tilde{\pi}_{H}^{C I}=\frac{\kappa s_{H}+x_{H}^{\prime}\left(s_{H}\right)}{\kappa s_{H}+x_{H}^{\prime}\left(s_{H}\right)+x_{I}^{C I}\left(c_{I}, c_{H}\right)}-c_{H} x_{H}^{\prime}\left(s_{H}\right)-c_{H} s_{H}=\frac{c_{I}^{2}}{\left(c_{I}+c_{H}\right)^{2}}-c_{H} s_{H}(1-\kappa) .
\end{aligned}
$$

Off equilibrium information is not truthfully revealed. Denote $x_{I}^{C I}\left(c_{I}, c_{j}\right)$ the incumbent's effort if he believes to face a newbie of type $j$ and denote $B R_{i}\left(x_{I}^{C I}\left(c_{I}, c_{j}\right) ; s_{i}\right)$ newbie type $i^{\prime} s$ best response against this effort of the incumbent, when he spent already $s_{i}$ on a signal. Then:

$$
\begin{aligned}
B R_{L}\left(x_{I}^{C I}\left(c_{I}, c_{H}\right) ; s_{H}\right) & =\sqrt{\frac{x_{I}^{C I}\left(c_{I}, c_{H}\right)}{c_{L}}}-x_{I}^{C I}\left(c_{I}, c_{H}\right)-\kappa s_{H} \\
B R_{H}\left(x_{I}^{C I}\left(c_{I}, c_{L}\right) ; s_{L}\right) & =\sqrt{\frac{x_{I}^{C I}\left(c_{I}, c_{L}\right)}{c_{H}}}-x_{I}^{C I}\left(c_{I}, c_{L}\right)-\kappa s_{L}
\end{aligned}
$$


This implies the newbie's utility, again from the perspective of the signaling stage, is as follows:

$$
\begin{aligned}
\tilde{\pi}_{L}^{D} & =\frac{B R_{L}\left(x_{I}^{C I}\left(c_{I}, c_{H}\right) ; s_{H}\right)+\kappa s_{H}}{B R_{L}\left(x_{I}^{C I}\left(c_{I}, c_{H}\right) ; s_{H}\right)+\kappa s_{H}+x_{I}^{C I}\left(c_{I}, c_{H}\right)}-c_{L} B R_{L}\left(x_{I}^{C I}\left(c_{I}, c_{H}\right) ; s_{H}\right)-c_{L} s_{H} \\
& =\frac{\left(c_{H}+c_{I}-\sqrt{c_{L} c_{H}}\right)^{2}}{\left(c_{H}+c_{I}\right)^{2}}-c_{L} s_{H}(1-\kappa) \\
\tilde{\pi}_{H}^{D} & =\frac{B R_{H}\left(x_{I}^{C I}\left(c_{I}, c_{L}\right) ; s_{L}\right)+\kappa s_{L}}{B R_{H}\left(x_{I}^{C I}\left(c_{I}, c_{L}\right) ; s_{L}\right)+\kappa s_{L}+x_{I}^{C I}\left(c_{I}, c_{L}\right)}-c_{H} B R_{H}\left(x_{I}^{C I}\left(c_{I}, c_{L}\right) ; s_{L}\right)-c_{H} s_{L} \\
& =\frac{\left(c_{L}+c_{I}-\sqrt{c_{L} c_{H}}\right)^{2}}{\left(c_{L}+c_{I}\right)^{2}}-c_{H} s_{L}(1-\kappa)
\end{aligned}
$$

In equilibrium it must be the case that $s_{H}=0$. Then, incentive compatibility requires

$$
\begin{aligned}
\frac{c_{I}^{2}}{\left(c_{I}+c_{L}\right)^{2}}-c_{L} s_{L}(1-\kappa) & \geq \frac{\left(c_{H}+c_{I}-\sqrt{c_{L} c_{H}}\right)^{2}}{\left(c_{H}+c_{I}\right)^{2}} \\
\frac{c_{I}^{2}}{\left(c_{I}+c_{H}\right)^{2}} & \geq \frac{\left(c_{L}+c_{I}-\sqrt{c_{L} c_{H}}\right)^{2}}{\left(c_{L}+c_{I}\right)^{2}}-c_{H} s_{L}(1-\kappa) .
\end{aligned}
$$

Note that, if $\kappa=0$, this condition is exactly the condition for separation we found above with binary types. Moreover, as it was the case there, there exists $s_{L}>0$ such that separation is possible if and only if $c_{I}>\sqrt{c_{L} c_{H}}$. Finally, also note that when $s_{L}$ is chosen such that the untalented newbie's IC constraint is just binding,

$$
s_{L}(\kappa)=\frac{\frac{\left(c_{I}-\sqrt{c_{H} c_{L}}+c_{L}\right)^{2}}{\left(c_{I}+c_{L}\right)^{2}}-\frac{c_{I}{ }^{2}}{\left(c_{I}+c_{H}\right)^{2}}}{c_{H}(1-\kappa)},
$$

the incumbent's IC constraint holds and $\kappa \cdot s_{L}(\kappa)<x_{L}^{C I}$, which can be checked readily. It is easily checked that $s_{L}(\kappa)$ increases in $\kappa$, implying showing off increases as signaling becomes more productive. If we refine the incumbent's beliefs using the intuitive criterion due to Cho and Kreps (1987), the game has a unique equilibrium in which the talented newbie shows off and types separate. Similar steps establish that, again as before with $\kappa=0$, a separating equilibrium cannot exist if $c_{I}<\sqrt{c_{L} c_{H}}$.

\section{References}

Acemoglu, D. and Robinson, J. A. (2016). Paths to inclusive political institutions. Working Paper.

Banks, J. S. and Sobel, J. (1987). Equilibrium selection in signaling games. Econometrica, $55(3): 647-661$.

Bernheim, B. D. (1994). A theory of conformity. Journal of Political Economy, 102(5):841-877.

Bowles, S. and Polanía-Reyes, S. (2012). Economic incentives and social preferences: Substitutes or complementes? Journal of Economic Literature, 50:368-425.

Brown, J. (2011). Quitters never win: The (adverse) incentive effects of competing with superstars. Journal of Political Economy, 119(5):982-1013.

Chlosta, K., Pull, K., and Futagami, S. (2014). Tournament structures in Japan and the U.S.: Why are they different and will they change? Management and Organizational Studies, 1:63-71. 
Cho, I.-K. and Kreps, D. M. (1987). Signaling games and stable equilibria. The Quarterly Journal of Economics, 102(2):179-221.

Chowdhury, S. M. and Gürtler, O. (2015). Sabotage in contests: a survey. Public Choice, 164(1):135-155.

Clark, D. J. and Nilssen, T. (2013). Learning by doing in contests. Public Choice, 156(1):329-343.

Clark, D. J. and Riis, C. (1998). Competition over more than one prize. American Economic Review, 88:276-289.

Cowgill, B. (2015). Competition and productivity in employee promotion contests. Technical report.

Crutzen, B. S. Y., Swank, O. H., and Visser, B. (2013). Confidence management: On interpersonal comparisons in teams. Journal of Economics and Management Strategy, 22(4):744-767.

Daley, B. and Green, B. (2014). Market signaling with grades. Journal of Economic Theory, 151:114-145.

Daughety, A. F. and Reinganum, J. F. (2014). The effect of third-party funding of plaintiffs on settlement. The American Economic Review, 104(8):2552-2566.

Denter, P. and Sisak, D. (2015). Do polls create momentum in political competition? Journal of Public Economics, 130:1-14.

Denter, P. and Sisak, D. (2016). Head starts in dynamic tournaments? Economics Letters, 149:94-97.

Dixit, A. K. (1987). Strategic behavior in contests. American Economic Review, 77(5):891-98.

Ederer, F. (2010). Feedback and motivation in dynamic tournaments. Journal of Economics 83 Management Strategy, 19:733-769.

Fallick, B., Fleischman, C. A., and Rebitzer, J. B. (2006). Job-hopping in silicon valley: Some evidence concerning the microfoundations of a high-technology cluster. The Review of Economics and Statistics, 88(3):472-481.

Fehr, E. and Fischbacher, U. (2004). Social norms and human cooperation. TRENDS in Cognitive Sciences, 8(4):185-190.

Feltovich, N., Harbaugh, R., and To, T. (2002). Too cool for school? signalling and countersignalling. RAND Journal of Economics, 33(4):630-649.

$\mathrm{Fu}, \mathrm{Q}$. and Lu, J. (2012). Micro foundations of multi-prize lottery contests: a perspective of noisy performance ranking. Social Choice and Welfare, 38:497-517.

Fudenberg, D. and Levine, D. K. (2014). Recency, consistent learning, and nash equilibrium. Proceedings of the National Academy of Sciences, 111(Supplement 3):10826-10829.

Fudenberg, D. and Levine, D. K. (2016). Whither game theory? towards a theory of learning in games. The Journal of Economic Perspectives, 30(4):151-169.

Gradstein, M. and Konrad, K. A. (1999). Orchestrating rent seeking contests. Economic Journal, 109(458):536-45. 
Heijnen, P. and Schoonbeek, L. (2017). Signaling in a rent-seeking contest with one-sided asymmetric information. Journal of Public Economic Theory, 19(2):548-564.

Hörner, J. and Sahuguet, N. (2007). Costly signalling in auctions. The Review of Economic Studies, $74(1): 173-206$.

Katsenos, G. (2009). Long-term conflict: How to signal a winner? Technical report, University of Hannover.

Klein, A. H. and Schmutzler, A. (2017). Optimal effort incentives in dynamic tournaments. Games and Economic Behavior, 103:199-224.

Klumpp, T. and Polborn, M. K. (2006). Primaries and the new hampshire effect. Journal of Public Economics, 90(6-7):1073-1114.

Kolb, A. M. (2015). Optimal entry timing. Journal of Economic Theory, 157:973 - 1000.

Konrad, K. A. (2009). Strategy and dynamics in contests. Oxford University Press.

Konrad, K. A. and Kovenock, D. (2009). Multi-battle contests. Games and Economic Behavior, $66(1): 256-274$.

Kovenock, D., Morath, F., and Münster, J. (2015). Information sharing in contests. Journal of Economics $\& 3$ Management Strategy, 24(3):570-596.

Lu, J., Ma, H., and Wang, Z. (2016). Ranking disclosure policies in all-pay auctions with incomplete information. Working Paper.

Malmendier, U. and Tate, G. (2005). CEO Overconfidence and Corporate Investment. Journal of Finance, 60(6):2661-2700.

Malmendier, U. and Tate, G. (2015). Behavioral CEOs: The Role of Managerial Overconfidence. Journal of Economic Perspectives, 29(4):37-60.

Mas-Colell, A., Whinston, M., and Green, J. (1995). Microeconomic Theory. Oxford University Press.

Moldovanu, B. and Sela, A. (2001). The optimal allocation of prizes in contests. American Economic Review, 91(3):542-558.

Moldovanu, B. and Sela, A. (2006). Contest architecture. Journal of Economic Theory, 126(1):7096.

Name Correa, A. J. and Yildirim, H. (2016). "Giving" in to social pressure. Games and Economic Behavior, 99:99-116.

Nti, K. O. (1999). Rent-seeking with asymmetric valuations. Public Choice, 98(3-4):415-30.

Parravano, M. and Poulsen, O. (2015). Stake size and the power of focal points in coordination games: Experimental evidence. Games and Economic Behavior, 94:191-199.

Payne, R. J. H. and Pagel, M. (1997). Why do animals repeat displays? Animal Behavior, 54(1):109-119. 
Scheel, D., Godfrey-Smith, P., and Lawrence, M. (2016). Signal use by octopuses in agonistic interactions. Current Biology, 26(3):377-382.

Seel, C. and Strack, P. (2016). Continuous time contests with private information. Mathematics of Operations Research, 41(3):1093-1107.

Sisak, D. (2009). Multiple prize contests: The optimal allocation of prizes. Journal of Economic Surveys, 23(1):82-114.

Sliwka, D. (2007). Trust as a signal of a social norm and the hidden costs of incentive schemes. American Economic Review, 97:999-1012.

Spence, M. (1973). Job market signaling. The Quarterly Journal of Economics, 87(3):355-374.

Van den Steen, E. (2004). Rational Overoptimism (and Other Biases). American Economic Review, 94(4):1141-1151.

Wu, Z. and Zheng, J. (2017). Information sharing in private value lottery contest. Economics Letters, 157:36-40.

Yildirim, H. (2005). Contests with multiple rounds. Games and Economic Behavior, 51(1):213227.

Zelmer, J. (2003). Linear public goods experiments: A meta-analysis. Experimental Economics, 6:299-310.

Zhang, J. and Zhou, J. (2016). Information Disclosure in Contests: A Bayesian Persuasion Approach. The Economic Journal, 126(597):2197-2217. 